\title{
LAS ANOTACIONES MARGINALES DE JOSÉ GAOS EN IDEAS I *
}

ANTONIO ZIRIÓN QUIJANO

INSTTTUTO DE INVESTIGACIONES FILOSÓFICAS

UNIVERSIDAD NACIONAL AUTÓNOMA DE MÉXICO

\section{Introducción}

En un ejemplar de la tercera edición (1928) de las Ideen zu einer reinen Phänomenologie und phänomenologischen Philosophie de Husserl, ${ }^{1}$ que se conserva en la biblioteca "Dr. Eduardo García Máynez" del Instituto de Investigaciones Filosóficas de la Universidad Nacional Autónoma de México, se encuentra una serie de anotaciones a lápiz, todas ellas del puño y letra de José Gaos, cuya significación filosófica las hace en mi opinión dignas de transcripción y reseña. Este ejemplar (al cual me referiré en adelante con la sigla E) perteneció sin duda a Gaos, y parece fácil suponer incluso que fue el que utilizó para hacer su traducción al español de la obra, y que por lo tanto la fecha de las anotaciones coincide, así sea aproximadamente, con la de esta traducción. ${ }^{2}$ Sin embargo, el hecho de que Gaos haya conocido, estudiado y comentado la obra muchos años antes de traducirla - junto con algún otro dato que señalaré en el curso de esta reseña- permite conjeturar que por lo menos algunas de las anotaciones también son mucho más antiguas que la traducción o, en todo caso, que la fecha de su publicación. Además, con la excepción de unos números de referencia en la página 315 ( $\mathrm{y}$ las pocas que se hallan en el "Sachregister"), las anotaciones faltan totalmente a partir de la página 244 (últimos párrafos del $\S 117$ ), por lo que, si las actividades de anotación y traducción corrían parejas, habría que concluir que Gaos se sirvió de otro ejemplar para traducir por lo menos estas últimas páginas (244-323). En vista de todo ello, y de otras circunstancias de menor monta, ${ }^{3}$ no parece posible guiarse por la fecha de la traducción para establecer la de las anotaciones.

Pero aunque sería deseable - biográfica e históricamente- conocer la fecha de las anotaciones, su interés principal no depende en modo alguno del momento en que fueron escritas. Esto es cierto, al menos, si lo que primordialmente nos interesa al transcribirlas no es escudriñar y esclarecer

- Este trabajo está dedicado al doctor Fernando Salmerón. 
aspectos y coyunturas escondidos del desarrollo intelectual y filosófico de Gaos, o rastrear detalles hasta ahora desconocidos de la historia de la producción y difusión en castellano de un libro medular de Husserl, sino dar a conocer, para que puedan evaluarse y estudiarse con detenimiento, los testimonios de una brillante y aguda confrontación de ideas y pensamientos. Aguda, no solamente porque Gaos represente o encarne una posición que puede considerarse abismalmente distanciada de la de Husserl (un "irracionalismo antinomista entre realismo e idealismo" 4 heredero del raciovitalismo y perspectivismo de Ortega y Gasset y entintado de personismo, de biografismo, de escepticismo, de. .. ), sino porque, como lo ponen de manifiesto la cantidad e índole de las anotaciones mismas (las transcritas aquí y con creces las no transcritas), ${ }^{5}$ su lectura de Ideas I fue extraordinariamente meticulosa, concienzuda, científica, al grado de que sus anotaciones dan a veces la impresión de haber sido hechas con un bisturí y no con un lápiz. Y brillante, no solamente por la sagacidad del anotador, sino porque el mero choque de las ideas en conflicto tiene la virtud de iluminar de chispas críticas el texto - si bien es cierto que algunas de éstas parecen más bien fruto de cortocircuitos o roces ciegos. Pero hasta en estos casos creo que es posible obtener algunas luces de valor tanto para la inteligencia de la obra de Husserl como para la de su recepción y crítica por parte de otras corrientes filosóficas.

La mayoría de los comentarios de Gaos que transcribo caen en dos grupos bien definidos: los que desde una posición neutral, por así decirlo, señalan alguna dificultad intrínseca del texto de Husserl o algún punto filosófico particular "objetivamente" controvertible, y los que ponen de manifiesto desacuerdos y beligerancias derivados del enfrentamiento de las posiciones filosóficas. Son estos últimos, obviamente, los que mejor nos acercan al pensamiento de Gaos; pero los primeros revelan mejor, tal vez, algunas tramas conceptuales de Ideas I que requieren particular atención. En todo caso, dejo a cargo del lector el juicio último sobre el valor de todos ellos.

Por otra parte, debo aclarar desde luego que mis propios y escasos comentarios se limitarán a hacer algunos señalamientos contextuales muy someros, algunas aclaraciones más o menos superficiales, y en ningún caso intentarán tocar el fondo del asunto. Ya extraer de las palabras de Gaos todas sus vinculaciones, su sentido y alcance, exigiría un estudio de su obra que no hemos hecho; y si a eso le sumamos la posible revisión de la obra de Husserl (y no sólo de Ideas I) en busca de ampliación o de respuesta, la tarea se volvería ingente y para mí francamente irrealizable. Además, en cuanto a lo primero, tampoco creo que la comprensión de las anotaciones de Gaos requiera que se tenga presente su obra filosófica o su filosofía en su integridad; pero en todo caso, lo que a este respecto se precise procuraré 
aportarlo en mis propios comentarios. Y en cuanto a lo segundo, tampoco he encontrado razones suficientes para adelantarme a la indagación y al juicio que el lector interesado y atento hará de todos modos por sí mismo.

Pero a pesar de lo dicho, en la sección que sigue hago una breve exposición de las opiniones de Gaos sobre Husserl, que no solamente servirá como ayuda para la comprensión, sino que dará el marco dentro del cual resulta obligado colocar las anotaciones que aquí se transcriben. En esta exposición, como será obvio, ni he pretendido ser exhaustivo, ni he puesto las afirmaciones citadas en el justo contexto del pensamiento de Gaos, ni he intentado tampoco ninguna crítica de fondo de las ideas reseñadas. $Y$ como en ella no me refiero más que incidentalmente a las anotaciones mismas, su lectura puede ser omitida sin trastorno alguno por quien no crea necesitarla.

\section{Gaos sobre Husserl}

Acaso ningún otro filósofo o profesor de filosofía mexicano se ha adentrado tanto en las obras y el pensamiento de Husserl como José Gaos (19001969), que tomó a México como segunda y definitiva patria en 1938, y ciertamente nadie ha hecho tanto como él -directa o indirectamente, a través de cursos, conferencias, ensayos, traducciones - para dar a conocer la fenomenología en este país. Además, el momento en que Gaos conoció el pensamiento de Husserl, o las obras de éste que él mismo llamaría "clásicas" (las Investigaciones lógicas e Ideas I, precisamente), fue en cierto modo privilegiado: durante los años veintes el deslumbramiento que la nueva fenomenología podía provocar propiciaba una excelente disposición para su estudio y discusión. Gaos participó en buena medida de estos entusiasmos iniciales - que para él duraron alrededor de diez años-, 6 y aunque su interés por Husserl no decayó más que relativamente cuando ellos declinaron, puede sin duda decirse que su concepción de la fenomenología husserliana quedó determinada casi por completo en esa primera etapa de contacto y asimilación. Pero haya sido por interés cabal o por cabal responsabilidad profesional, el hecho es que Gaos no dejó nunca de dedicarle atención y empeños a la fenomenología.

Su serie de traducciones al español de obras principales de Husserl -entre las cuales la de Ideas I no fue la primera, sino la última $-{ }^{7}$ no fue el menor de los frutos de esta dedicación, aunque tampoco fue en modo alguno el único. Ya en el mismo año en que apareció la primera de ellas (1929), 8 escribió, para presentarlo en oposiciones a cátedra, un texto titulado "Introducción a la fenomenología", que permaneció inédito hasta $1960 .{ }^{9}$ En la primera parte de esta "Introducción" (la segunda es un "Apéndice histórico-bibliográfico") se hace, según afirma el mismo Gaos, "una exposición de la fenomenología de Husserl en la forma definitiva en que este mismo la ha expuesto en sus 
Ideas" (IF, p. 17), definida, "en pocas palabras", como "la ciencia eidética descriptiva de los fenómenos puros que integran la conciencia pura" (IF, p. 18). En el prólogo del volumen que citamos, redactado en 1960, Gaos explica:

Después de un relativo eclipse, causado sobre todo por el paso del existencialismo, goza la filosofía de Husserl de una nueva predilección, entre los filósofos de las más recientes promociones y los discipulos y el público todo de éstos. Cierto que la predilección se dirige a las últimas publicaciones póstumas y a las inéditas del fundador de la fenomenología. Pero no menos cierto, que la introducción a su filosofía será siempre la introducción en la fenomenología de las dos publicaciones ya clásicas, las Investigaciones puestas en la segunda edición al nivel de las Ideas y éstas. Y el trabajo de que se trata pudiera ser tal introducción en un sentido muy riguroso, en el que no tiene el autor noticia de otra: un sentido al par teórico e histórico, por partir de la visión del mundo del "hombre ingenuo", transitar a las filosofías predominantes cuando inició Husserl la suya, y seguir a ésta paso a paso desde su iniciación hasta el núcleo de su esencia. (IF, Prólogo, p. 11 s.)

Didácticamente, el trabajo se estructura como una delimitación de "los objetos del fenomenólogo" frente a "los objetos antes de la fenomenología" (los del "hombre ingenuo", los del "hombre de ciencia", los del "filósofo positivista", los del "filósofo idealista"). La delimitación culmina en un resumen que está en total acuerdo con la definición de fenomenología estipulada: "El objeto de la fenomenología se alcanza e investiga, en suma, en dos etapas metódicas. Primero, hay que obtener la conciencia pura mediante las reducciones fenomenológicas. Y luego hay que practicar la reducción eidética que eleva de la conciencia pura a su esencia, para aplicar a ésta el método eidético" (IF, p. 80). Pero a pesar de la claridad de este esquema, la exposición que hace Gaos de ambas reducciones con el rubro de "El método fenomenológico" puede dar lugar a confusiones por lo menos en dos de sus puntos: el primero es la consideración de la reducción eidética propiamente dicha como una aplicación de la epoché fenomenológica, y el segundo es la denominación de "reducción eidética" también a la reducción propiamente fenomenológica de las esencias y las respectivas ciencias eidéticas (expuesta en el $\S 60$ de Ideas I). Justamente la relación entre ambas "reducciones" (la eidética y la fenomenológica), su precisa delimitación recíproca, su función dentro del "método fenomenológico" y su papel en la definición de la fenomenología y de su objeto de estudio, constituyen temas muy sensibles dentro de la comprensión y la exposición de las ideas de Husserl por parte de Gaos. En todo caso, ya en este primer trabajo se pone de manifiesto un punto clave de su interpretación de la fenomenología: la idea de que ésta 
consta de dos partes, que corresponden a las dos "reducciones" (o "etapas metódicas"). ${ }^{10}$

Por esos mismos años se ocupó Gaos, en su tesis de doctorado, de la crítica al psicologismo que Husserl lleva a cabo en los "Prolegómenos a la lógica pura". ${ }^{11}$ La toma de posición de Gaos en este trabajo de tesis es muy importante para evaluar sus opiniones sobre Husserl - y luego algunos de los comentarios que se presentan abajo. Años después (en 1940), Gaos mismo resumió el sentido de su tesis de la siguiente manera: " $L a$ crítica del psicologismo en Husserl es un intento por examinar la validez de esta crítica, considerada como fundamental para la superación del positivismo del siglo XIX y la restauración del idealismo platonizante de las ideas y los valores en el siglo XX. El examen muestra que la crítica está fundada en un concepto empirista de los hechos, inaplicable al hecho de la existencia humana." 12 Ya en una nota de la tesis, afirmaba: "En general, los autores señalan cómo de la crítica del psicologismo pasó Husserl a la fenomenología. [... ] Pero ninguno ha subrayado expresamente hasta qué punto la argumentación de Husserl, en apariencia tan concluyente y de hecho tan decisiva, no es, ni lo uno, ni lo otro, sino ella misma tan íntimamente problemática como toda la filosofía, justamente por suponer los problemas (que no soluciones) más lejanos y más profundos de la fenomenología y de la filosofía actual —de la filosofía en general."13

En efecto, la parte crítica de la tesis (que ocupa aproximadamente la mitad de espacio que la parte expositiva) comienza planteando la interpretación según la cual la crítica del psicologismo, más allá de su "finalidad estricta y expresa", debe ser considerada "desde el punto de vista de su significación histórica, o como toda una superación del positivismo y fundamentación del ser ideal" (IF, p. 144). Y la crítica de Gaos se ejerce justamente examinando "hasta qué punto la crítica del psicologismo lógico hecha por Husserl tiene este valor de superación del positivismo y fundamentación del ser ideal" (ibid.). En su parte central, quiere hacer ver que la crítica de Husserl "suponía resueltos [... ] los principales problemas filosóficos del ser ideal" y en primer lugar "la existencia efectiva de este ser" (IF, pp. 156157). Pues en esa crítica funcionan como supuestos tanto la tesis de que las leyes lógicas no son leyes de hechos, como su consecuencia lógica de que son leyes de unos objetos que no son hechos. Husserl apela a la evidencia y exactitud de las leyes lógicas "como instancia última", con el objeto de "mostrar directamente que las leyes lógicas son distintas por su validez y por sus objetos de las leyes psicológicas" (ibid.). Pero entonces el punto de partida, la premisa, el supuesto de toda la crítica, es la "percepción directa del ser ideal que no logra articularse como demostración lógica de su existencia -acaso porque este ser no admita otra demostración de su existencia que 
la percepción de ésta- ¿y qué más prueba pudiera pedirse de la existencia de ser alguno que percibirle a él mismo, existiendo delante de nosotros? He aquí cómo la crítica de Husserl supone resuelto el problema de la existencia efectiva del ser ideal" (ibid.). Gaos mismo resume:

La crítica de Husserl no constituye una demostración en forma de la existencia del orden ideal, un concluir esta existencia de determinadas premisas. Constituye una refutación del psicologismo y una fundamentación de la lógica pura a base de la existencia del orden ideal directamente percibido, mostrado e invocado. Su tendencia es a probar de un modo definitivo la existencia del orden ideal, negada por el positivismo, el del siglo XIX y el de otros siglos anteriores, problemática a lo largo de la historia entera de la filosofía, desde los presocráticos, por la evidencia y necesidad, la universalidad y exactitud de las leyes lógicas -que por tener estos caracteres no pueden ser leyes de hechos. Pero como antes de saber lo que son hechos y lo que no son hechos, de saber si existen, además de los hechos, otros objetos que no sean hechos, no podemos saber fundada, y no arbitrariamente, si leyes evidentes y necesarias, universales y exactas, son o no son, pueden o no pueden ser leyes de hechos, la realidad es que la crítica de Husserl prueba la evidencia y necesidad, la universalidad y exactitud de las leyes lógicas, y de las demás leyes de estos caracteres, y la imposibilidad de que leyes tales sean leyes de hechos, por la existencia, además de los hechos, de otros objetos que no son hechos, o sea, por aquella existencia del orden ideal -problemática a lo largo de la historia de la filosofía y descubierta en esta historia una vez más- no más, ni menos, problemáticamente. La crítica de Husserl, en conclusión, no es una prueba definitiva de la existencia del orden ideal, una fundamentación concluyente del idealismo objetivo. Es un momento heurístico relevante en la historia de la fenomenologia y de la ontologia contemporáneas, a través del cual ha proseguido la dialéctica histórica de la filosofía. (IF, p. 164.)

Pero Gaos descubre todavía una complicación interesante entre este tema y el de la refutación del escepticismo, que es otro punto medular de la crítica de Husserl. El escepticismo constituye "en su sentido riguroso y profundo" un votar "a favor de la radical contingencia y relatividad del ser ideal" (IF, p. 159); su refutación representa la adopción del llamado "idealismo objetivo", postura ontológica y por ende metafísica que consiste en "un votar por la necesidad del ser ideal y por la elevación de éste al rango del ser por excelencia, del ser primario, de quien, siendo él por sí, por no poder menos de ser absolutamente, reciben su ser relativo todas las restantes formas del ser" (ibid.). El ser ideal queda consagrado como ser absoluto. Pero además del escepticismo riguroso "en cuanto tesis" -que "es absurdo, porque es un contrasentido" (IF, p. 160) - hay, dice Gaos, "el escepticismo en cuanto actitud", el cual "no es absurdo más que en el supuesto de la necesidad del ser ideal" (IF, p. 161), en cuyo caso el escéptico ("la conciencia, la vida...") 
no podría dejar de "reconocer" o de "poner" el ser ideal. Pero justamente el ser ideal es problemático, y con él el mismo escepticismo. Gaos concluye que "no porque la tesis escéptica sea un contrasentido, hay que admitir el ser ideal, como pretende la crítica de Husserl, sino que más bien por ser, y ser necesariamente, el ser ideal, es la tesis escéptica un contrasentido" (IF, pp. 161 y 165).

Según Gaos, la posterior posición definitiva de Husserl, "la adjudicación del ser absoluto a la conciencia pura", que no es un idealismo objetivo, corrobora de alguna manera la conclusión de que la crítica del psicologismo no era una fundamentación concluyente de este idealismo. A partir de esa crítica, se ha llegado más bien "al replanteamiento del problema de la adjudicación del ser absoluto: ya al ser ideal -ya al ser de la conciencia pura-ya al ser de nuestra vida humana —que es el problema de la filosofía actual" (IF, p. 165).

Con todo ello, y como de paso, queda ya establecido en definitiva el concepto de fenomenología "como ciencia eidética descriptiva de los fenómenos - psíquicos-puros, fundada en la doble reducción, fenomenológica y eidética" ( $C P H$, nota $44 ; I F$, p. 184). Pero ahora resalta con más claridad que "en la fenomenología hay dos elementos o factores, uno eidético y otro psicológico, que han sido diversamente acentuados y armonizados" ( $\mathrm{CPH}$, nota 45; IF, pp. 184-185). En la interpretación de Gaos, Husserl habría transitado de uno de estos elementos o factores al otro y, tras haberle adjudicado el "ser absoluto" al ser ideal, concluye adjudicándoselo al ser de la conciencia. ${ }^{14}$

La interpretación de la crítica del psicologismo, y las ideas fundamentales de la crítica de Gaos, se sostienen y amplían en el volumen en que se plasma la polémica que sostuvo con Francisco Larroyo en torno al concepto de una "filosofía de la filosofía", Dos ideas de la filosofía. ${ }^{15}$ En medio de la polémica, Gaos reitera que "Husserl hizo la crítica del psicologismo a base de un concepto positivista (el medio se impone) de la psique como 'hechos' psíquicos, del hombre como especie y realidad 'empíricas'” (DI, p. 109), pero lo reitera para llamar la atención sobre el camino recorrido por la filosofía desde entonces "hasta nuestros días, en que se ha llegado a pensar que 'humanismo' e 'historicismo' no son 'psicologismo' ni 'empirismo', que el hombre no es un 'hecho', ni nada 'empírico', aunque sea una realidad, una realidad 'trascendental', no una idealidad 'trascendental' " (ibid.).

Y en otro pasaje, después de atribuir a Husserl un reforzamiento en nuestros tiempos del descubrimiento platónico de un orden del ser distinto del ser mudable y sensible, y de exponer de nueva cuenta la crítica del psicologismo de las Investigaciones lógicas -crítica que "debe considerarse 
como el decidido punto de partida de la obra entera de Husserl y de sus consecuencias históricas" (ID, p. 150)-, afirma:

Toda la filosofía de los objetos ideales gravita sobre la concepción de los objetos físicos y psíquicos como mudables, individuales y, en último término, temporales. Si los objetos físicos y psíquicos no se caracterizasen por tales notas, no habría fundamentos para distinguir de ellos los ideales por la posesión de las contrarias.

Así ya en el punto de partida contemporáneo de toda esta filosofía. La critica del psicologismo hecha por Husserl gravita entera sobre la concepción de los hechos en general y en particular de los hechos psíquicos como mudables, individuales y temporales, y de la especie como un hecho de esta indole. Si la especie no fuese un hecho de esta índole, o si la índole de todos los hechos no consistiese en mutabilidad, individualidad y temporalidad en el sentido indicado en lo anterior, los contrasentidos y absurdos encontrados no se darían y no habría fundamentos para formular las conclusiones de Husserl. (DI, pp. 168169.)

Gaos piensa, desde luego, que hay al menos un "hecho" que no posee dichos atributos: se trata, como se ha insinuado, de la vida humana misma, que "es un hecho en un sentido absolutamente distinto de todos los hechos" ( $D I$, p. 180); la vida humana que consiste en "vivirnos conviviendo" y que es "el hecho único, absoluto, al que se refieren, del que dependen en determinado sentido todos los demás hechos" (p. 179), "el hecho por excelencia, el único hecho en sentido absolutamente riguroso y fundamental" (pp. 179-180). Frente a este hecho concreto y absoluto de la vida humana, no solamente los objetos ideales, sino también los hechos en sentido tradicional, son abstracciones: abstracciones "correlativas" (p. 181). Asi pues, "si no nos representamos la convivencia humana como tal hecho físico abstracto [de la vida de una especie], sino como la vivimos, como el hecho sui generis y absoluto que es nuestra vida, no tenemos fundamento alguno para pretender la existencia de unos objetos ideales aparte de la realidad de la vida humana" (pp. 182-183). Pero además:

La idealidad es entendida como una idealidad trascendental, como una subjetividad trascendental, esto es, ideal: la trascendentalidad sería ideal. Todo lo precedente conduce a decir más bien: lo trascendental es nuestra vida; nuestra vida es una realidad trascendental; trascendentalidad, pero real.

Nuestra vida como realidad trascendental no es la abstracción de la conciencia, sino la realidad de la vida en su total concreción. (DI, p. 183.)

Desgraciadamente, nos llevaría muy lejos rastrear aquí los fundamentos o antecedentes de estas afirmaciones de Gaos y la significación que tienen dentro de su pensamiento. En todo caso, tampoco están desligadas de otras 
ideas que se encuentran en la misma obra y que vienen a situar bajo una nueva luz el concepto de la fenomenología como una ciencia estructuralmente "doble" o "dual". Haciendo el resumen de una de las conferencias suyas que dieron pie a la polémica con Larroyo, Gaos escribe:

Destinada [dicha conferencia] a hacer vivir momentáneamente a la asistencia el revivir la historia de la filosofía que constituye el meollo de la profesión filosófica en nuestros días y a fijar el sentido de esta experiencia histórica. La conferencia tomó como filosofía contemporánea singularmente adecuada a sus fines la fenomenología, con su doble constitución de contemplación de ideas y reflexión en la conciencia. Primero las ideas fueron presentadas como los principios substantes y salvadores. La vida filosófica, sobre la base de la abstracción ascética, como abstracción ideativa y participación salvadora en la beatitud divina: vida contemplativa y vida beata. A continuación se explicó el tránsito histórico de la filosofía antigua a la cristiana y moderna, contenido en forma estática en la dualidad estructural de la fenomenología, como fenómeno de la 'fluctuación de las ideas' y descubrimiento de un nuevo principio substante y salvador en la conciencia. Pero la duda metódica y la reducción fenomenológica pura, como intentos de abstracción de todo lo fluctuante, errar o error, conducen a una abstracción que es enajenación vital del mundo, de los demás y de Dios, que se evidencia y experimenta imposible empresa extremista de enajenación mental de sí mismo, de perdición irremisible e in-humanidad. ${ }^{16}$

Y cuando defiende ante Larroyo sus ideas - capitales, por cierto- de que la filosofía es en esencia soberbia y confesión personal, Gaos se refiere a la fenomenología de la siguiente manera:

La filosofía de la filosofía comprende una psicología del filósofo. Pero esta psicología, como toda psicología, no puede hacerse sino mediante conceptos que son objeto de fenomenología. Así la fenomenología de la soberbia es indispensable a la psicología del filósofo en cuanto soberbio. Pero hay, además, una fenomenología de la filosofía y del filósofo. Esta fenomenología, como toda fenomenología, debe hacerse a base de casos o ejemplares empíricos y puede hacerse a base de uno solo e incluso imaginario o ficticio, enseñanzas todas expresas de Husserl.

Pero, además, la fenomenología ha evolucionado desde Husserl hasta Heidegger en un sentido de creciente atención a los fenómenos humanos en la circunstancialidad que Ortega ha enseñado desde sus Meditaciones del Quijote. Husserl toma los fenómenos psíquicos en la abstracción en que los venía tomando la psicología general. Se ha visto, no sólo por la filosofía, sino también por la psicología (psicología concreta, caracterología), que los fenómenos humanos son concretos de aquellos y deben ser descritos y narrados, historiados, en esta su concreción, que es su sola autenticidad.

No hay inconciliabilidad entre una fenomenología de la filosofía y la definición de ésta como confesión personal. El concepto de confesión personal puede 
ser, es un concepto esencial y por ende tan susceptible de fenomenología como cualquier otro análogo: la 'confesión personal' es un eidos. Y este eidos puede, tiene que ser descrito a base de un caso particular, empírico, que aquí es, tiene que ser, por la naturaleza misma de las cosas, un caso personal. ${ }^{17}$

Independientemente de lo que pudieran enseñarnos acerca de otros aspectos de la filosofía de Gaos, las citas anteriores nos muestran otra faceta de su relación con la fenomenología: en un sentido que es husserliano por lo menos en la intención, el método fenomenológico es un método practicable. Es una confirmación más que suficiente de esto el empleo que el mismo Gaos hace de dicho método en las dos obras que constituyen, conjuntamente, lo que puede calificarse como "su" filosofía o su "sistema" filosófico, De la filosofía y Del hombre. ${ }^{18}$ La primera de ellas comienza por una "fenomenología de la expresión" que comprende la primera parte completa del curso en que la obra consiste; esta fenomenología se amplía luego en una "fenomenología de la razón" y una "fenomenología de las categorías", que constituyen la base sobre la cual Gaos teje las demás partes de su "filosofía de la filosofía": teoría de las categorías, antropología filosófica, teoría de la historia de la filosofía. ${ }^{19}$ Por su parte, "el método de la Antropología" expuesta en Del hombre "es ante todo un método fenomenológico, porque se trata de 'fenómenos' y no de 'objetos metafísicos', [... ], y de fenómenos que pueden analizarse descriptivamente, o describirse analíticamente, y deben serlo antes de cualquier otra operación metódica posible y debida con ellos". 20

Aunque el sentido preciso y la justificación del empleo de lo que en estas obras se entiende por "método fenomenológico", o por "fenomenología" (y de lo que en ellas se practica como tal), así como también su filiación husserliana, podrían ser tema de largas (y acaso no ininteresantes) discusiones, Gaos no les dedica en De la filosofía ninguna atención, ${ }^{21}$ y en Del hombre las despacha con unas cuantas palabras a todas luces insuficientes: "El método es fenomenológico en el sentido de la fenomenología fundada por Husserl, pero no en el de la filosofía idealista que Husserl la llevó a ser, sino en el sentido más libre de filosofías como la idealista y la realista en que lo entendieron, emplearon y cultivaron discípulos de Husserl y otros cultivadores de la Filosofía."22 Este método, que es algo en ciertos respectos más elaborado, y en otros un poco menos, que el escueto método de la "reducción eidética" y que es en algunos puntos semejante al que puede considerarse que Husserl expone implícitamente en las Investigaciones lógicas, ${ }^{23}$ viene a ser, en suma, el resultado de la comprensión peculiar de Gaos, no discutida ni razonada, por lo menos ante el lector. ${ }^{24}$

Lo anterior no impide, desde luego, que Gaos tenga razón cuando afirma en De la filosofía que "lo que debe a Husserl toda la fenomenología de la 
expresión de este curso, y a Brentano, Husserl, Scheler y Hartmann, y a Müller, la clasificación de los objetos por la presencia, es patente" (OC XII, p. 420).

En todo caso, está claro que Gaos mantuvo siempre respeto por este aspecto "metódico" de la fenomenología y afirmó (y aprovechó) la utilidad filosófica de lo que en su opinión era el "método fenomenológico". Esto debe sin duda vincularse retrospectivamente con su confesión de que prácticamente durante un decenio vivió "como la verdad filosófica una síntesis de fenomenología realista, mucho más de las esencias que de la conciencia, y de filosofía de los valores". ${ }^{25}$ Pues si bien la fenomenología fue solamente una entre las varias doctrinas o filosofías que vivió como la verdad, y esta misma sucesión de "verdades" durante su vida constituyó en última instancia un motivo de escepticismo, ${ }^{26}$ es indudable que al método fenomenológico, en el sentido difícil de precisar al que nos hemos referido, le concedió un valor de primer rango, ya que acabó por hacerlo formar una parte integrante, y fundamental, de su propia filosofía. ${ }^{27}$

Pero si bien el método fenomenológico (o la fenomenología, en alguna acepción apropiada de la palabra) podría entonces colocarse entre las partes o disciplinas "científicas" de la filosofía, frente y en oposición a las partes o disciplinas "metafísicas", ${ }^{28}$ Gaos sometió a una crítica expresa la idea -que para Husserl es central- de que la filosofía puede convertirse (y por lo tanto debe convertirse) en una ciencia rigurosa, y condenó además, severamente, el intento de Husserl por conseguirlo. La razón de la crítica quizá se halle resumida en esta nota:

Históricamente se ha pasado de la idea de un saber universal filosófico-científico a una ciencia especializada y colectiva sucesiva y en Husserl a una pretendida filosofía científica, que es un monstruo de contradicciones: pretendidamente no universal, en el sentido de parcial y colectiva sucesiva como la ciencia, y universal dentro de la vida individual de Husserl, en el sentido de los fundamentos de todas las ciencias, y, aunque sólo fuese por intermedio de ella, de todas las cosas; pretendidamente objetiva e intersubjetiva y efectivamente subjetiva. ${ }^{29}$

Pero a esta ecuación contradictoria en que según Gaos cae Husserl ("saber universal dentro de la vida individual = objetivo"), éste puede escapar, también según Gaos, postulando estas otras ecuaciones:

Saber de los fundamentos de todo = saber universal asequible dentro de la vida individual.

Saber de los fundamentos de todo = saber parcial susceptible de objetividad e intersubjetividad universal. (lbid., p. 145.) 
Pero entonces, aparentemente, la razón de la crítica de Gaos no es una razón, sino un hecho: "Pero la historia de Husserl inserta en la entera de la filosofía muestra que de hecho no ha sido así hasta hoy, y mueve a indagar la posible imposibilidad de que sea así y la razón de ser de ella" (p. 145). ${ }^{30}$ ¿Ha dado Gaos la razón de ser de esta imposibilidad? No podemos discutirlo aquí, aunque hay que asentar que Gaos cree haberla dado, no solamente en la continuación de las "Notas" citadas, sino sobre todo y principalmente en De la filosofía y Del hombre. ${ }^{31}$ En todo caso, no hay duda de que la indagación de esa razón de ser constituyó el principal leit motiv del filosofar de Gaos durante toda su vida.

La condena del intento husserliano por convertir a la filosofía en una ciencia rigurosa se apoya en el hecho de que Husserl "pensó que los fundamentos de toda ciencia eran las esencias y la conciencia pura - pero ésta es una de las ideas más precipitadas, más apriorísticas, menos científicas, de toda la historia de la filosofía" (ibid., p. 147); así, "quiso hacer la ciencia de los fundamentos de todas las ciencias e hizo una filosofía más de los principios de todas las cosas" (ibid., p. 148). Pero "los fundamentos de las ciencias deben sacarse de las ciencias como los de las cosas de las cosas. Es seguro que Husserl no sacó de las ciencias sus fundamentos de las ciencias. [...] Es probable, incluso, que, a pesar del 'Zurück zu Sachen', no sacase de las cosas sus fundamentos de ellas, las esencias y la conciencia pura" (ibid.). ${ }^{32}$

Consigno, por último, la ponencia que presentó Gaos en el "Simposio sobre la noción husserliana de la Lebenswelt", que se llevó a cabo en 1963 dentro del XIII Congreso Internacional de Filosofía que tuvo lugar en México, ponencia titulada "La Lebenswelt de Husserl". ${ }^{33}$ Lo principal de la posición de Gaos se encuentra aquí, me parece, en dos ideas: en primer lugar, la que presenta la posibilidad de que la fenomenología -entendida como "explicación de los objetos de la subjetividad por ésta", como "la especie por excelencia del género 'filosofía trascendental': exponer las condiciones de posibilidad de un existente, de lo existente - como dadas en un sujeto" (p. 21) - sea "ciencia por ser aquello por lo que las ciencias son ciencias según Husserl: abstracta, general - y objetiva" (p. 24); y tendría que serlo "si la reducción fenomenológica stricto sensu acarrease de suyo la reducción eidética, si objetivarse la subjetividad trascendental misma, objetivando sus correlatos objetivos como meros fenómenos para ella, requiriese un abstraer de los vínculos individuantes con lo concreto, que daría por resultado un abstraerse en lo general, lo eidético de lo concreto, o si 'fenómeno' en este sentido husserliano no pudiese ser, por fuerza de la naturaleza de las cosas, sino 'esencia', eidos" (p. 24). En segundo lugar, la que presenta el obstáculo, el gran "pero": "Mas ¿y si la única forma de objetivar lo individual, lo concreto mismo, fuese la forma concreta, indivi- 
dual, la única rigurosamente tal, de la - autobiografía, o por lo menos del hablar en primera persona, individuando así el lenguaje?" (p. 24). Con ello se daría la preferencia, en última instancia, al "término realista ingenuo" de la antinomia entre el "realismo ingenuo" y el "idealismo trascendental" que Gaos ha formulado así: "Pues bien ¿y si la dualidad del realismo ingenuo y el idealismo trascendental fuese la de los términos de una antinomía, en el sentido de una dualidad de concepciones de ninguna de las cuales fuese posible predicar la verdad, predicando correlativamente de la otra la falsedad, sino que lo único posible fuese 'optar', por 'motivos' irracionales, por la una y no por la otra? iy si Husserl hubiese optado por el idealismo trascendental, por los motivos irracionales que fuesen?..." (p. 23).

\section{Los comentarios sobre Ideas I}

Dejando a un lado los subrayados, que abundan, las anotaciones pueden agruparse, con alguna flexibilidad, en cuatro categorías:

(1) Las que llamaremos descriptivas. Éstas son, con mucho, las más numerosas. Ocurren exclusivamente en los márgenes laterales exteriores del texto (a la izquierda en páginas pares, a la derecha en las nones). Consisten en una indicación del tema de que trata el parágrafo o el pasaje respectivo; son una suerte de encabezados, puestos seguramente con el fin de ayudarse en la localización durante el estudio o la exposición de la obra en clase. A veces, más que encabezados descriptivos parecen anotaciones destinadas a destacar gráficamente relaciones conceptuales presentes en el texto y facilitarse así su comprensión.

(2) Las notas que podemos llamar de traducción. Son muy escasas en comparación con las anteriores, y se hallan siempre en los márgenes laterales interiores (a la derecha en páginas pares, a la izquierda en las nones). La mayoría consiste, sencillamente, en palabras o frases que traducen alguna palabra o frase que se encuentra en la misma línea. Algunas de esas palabras van seguidas de un signo de interrogación. El cotejo con la traducción publicada revela que muy pocas de estas palabras o frases fueron elegidas en definitiva por Gaos. ${ }^{34}$

(3) Los que llamaremos números de referencia. Son un poco menos numerosos que las notas descriptivas, y se hallan como ellas en los márgenes exteriores. Consisten en números o series de números que remiten a otros lugares de la obra, pertinentes (al menos en la muy confiable apreciación de Gaos) por la relación temática que guardan con el pasaje en que los números se encuentran. Normalmente, constan del número o números de página y, separado por una coma, el número del párrafo o, a veces, el nú- 
mero de un pasaje que Gaos mismo ha numerado. A veces el número remite explícitamente a un parágrafo (§) determinado.

(4) Finalmente, los comentarios, que son con mucho las anotaciones más significativas. La mayoría se encuentra en los márgenes superior e inferior del texto, y casi todos en este último. Casi todos también están introducidos por una llamada (un número entre paréntesis) puesta en el margen lateral exterior en el lugar del texto sobre el que recae el comentario, y repetida también, obviamente, al inicio de la anotación.

En lo que sigue se da la transcripción completa solamente de estos comentarios (4), aunque en ocasiones resulta imposible omitir anotaciones de los grupos (1) y (3) debido al entrelazamiento en que -como se veráse encuentran con las de (4).

La transcripción de cada anotación está precedida por una línea en la que se dan las referencias de su localización: primero en $\mathrm{E}$, y luego, entre paréntesis, en Hua III/ 1 , abreviado como ' $\mathrm{H}$ ', ${ }^{35}$ y en la más reciente edición de la versión española de Gaos, la de $1986,{ }^{36}$ abreviada como 'C'. Los números de página se dan en negritas; los de línea, en tipo normal. Se cuentan como líneas las de los títulos de las diferentes secciones de la obra, y téngase además en cuenta que las "llamadas" de Gaos a sus propias anotaciones no necesariamente se refieren a una sola línea y a veces no parecen caer, porque se lo estorban otras anotaciones, en el lugar en que Gaos las habría puesto sin estorbos. ${ }^{37}$ Cuando en una sola página aparecen varias llamadas iguales (o sea, que remiten a la misma anotación), sus referencias se agrupan en una sola línea. Por otra parte, cuando me ha parecido que entre las anotaciones marginales de Husserl en sus propios ejemplares (publicadas en Hua III/2, p. 477) ${ }^{38}$ hay alguna pertinente en algún respecto al punto tratado por Gaos en su comentario, doy en una nota (señalada con una letra voladita) la referencia de $H u a$ III/2 y la página de $H u a$ III/1 (H) sobre la cual recae la anotación de Husserl.

En las transcripciones propiamente dichas, utilizamos las siguientes abreviaturas: $M=$ anotación en el margen externo; $I=$ anotación en el margen interno; $P=$ anotación al pie (margen inferior de la página); $R=$ anotación en el margen superior de la página; $D=$ Lo que sigue se encuentra debajo de lo precedente.

' $D$ ' se usa en algunos casos en que resulta práctico indicar así la disposición de la anotación; en otros, la disposición se intenta reproducir gráficamente. Mis aclaraciones dentro de las anotaciones están enmarcadas por los símbolos ' " y van en cursivas. Mis comentarios están separados de las transcripciones y formados con doble sangría. 
En los comentarios de Gaos se presentan aquí y allá dos abreviaturas cuyo sentido es fácil establecer: 's.l.' = 'sentido lato', y 's.e.' = 'sentido estricto'. Para una tercera abreviatura muy frecuente, 'cap', tenemos (tras mucho pensar) solamente una conjetura: 'cuestión a pensar'. Las abreviaturas 'P.s.' y 'Pa.' (que se hallan únicamente en las notas de $\mathrm{E} 9,5,20$ y E 10,16) significan, sin duda, 'página siguiente' y 'página anterior', respectivamente. Otras abreviaturas son comunes y no requieren interpretación, pero en algunos casos expreso mi duda con un signo de interrogación. Los números que da Gaos en sus anotaciones son - a menos que se indique otra cosa- números de página seguidos del número de párrafo en esa página.

E $1,3(\mathrm{H} 3,2 ; \mathrm{C} 7,3)$

M Soberbia

El mismo señalamiento o "comentario" se encuentra en éste y en otros seis pasajes posteriores. En diversas ocasiones y con variados énfasis Gaos expresó su idea o su teoría de que la esencia (o sustancia) de la filosofía es la soberbia, o más aún, la soberbia luciferina ${ }^{39}$ e incluso intentó "mostrar cómo la esencia de la Filosofía y la esencia de la soberbia coinciden fenomenológicamente rasgo por rasgo". ${ }^{40} \mathrm{El}$ vínculo esencial lo halla Gaos en los principios, por los que el filósofo se afana, de los que quisiera saberse dueño, y que son para él lo supremo y el instrumento de dominación de todo y sobre todo. ${ }^{41}$

E 2,1 (H 3,31; C 7,27)

M Soberbia

E 3,11-15 (H 5,15-19; C 9,9-13)

$M ?$ ? El signo de interrogación abarca las cinco líneas.»

E 5,26 (H 8,1; C 11,34)

M Soberbia 
E 9,5,20 (H 12,16,31; C 19,12,28)

$M$ (1) $P$ (1) La esencia de cada hecho y la esencia del hecho. Ps.(1) $D$ Cap. ¿Y el hecho del individuo absoluto?

Con el término de "individuo absoluto" Gaos se refiere probablemente a su propio concepto de "nuestra vida", que es un hecho sui generis, o acaso también al sujeto o yo de la conciencia absoluta de Husserl (cfr. § 49). En todo caso, es obvio que la pregunta quiere destacar la dificultad de una concepción de un "individuo absoluto" en vista de la idea de que "el ser individual de toda índole es [... ] 'contingente". Por otra parte, el tema de los conceptos individuales, o sea, el de la individualidad justamente en relación con la conceptualidad, la idealidad o la esencialidad, tiene un papel muy destacado dentro de la fenomenología de la expresión que Gaos desarrolla en De la filosofía y Del hombre. ${ }^{42}$

E 10,16 (H 13,30; C 20,26)

$M$ (1) $P$ (1) Las esencias de lo intuíble sólo por un lado ison ellas mismas realmente intuíbles sólo por un lado? P.a.(1)

E $11,17,23,26,38$ (H 15,4,10-11,14,35n; C 21,33,22,5-6,9,34n)

$M$ (1) $P$ (1) ¿Hay realmente representación de las esencias? ¿de todo objeto?

Nótese que en el texto alemán no es un único término el que corresponde a "representación" en todos los lugares señalados. En los dos primeros corresponde a Vorstellung; en el tercero a Vergegenwärtigung; en el último el término no aparece. Puede venir al caso apuntar, por otra parte, que Gaos niega la existencia de "imágenes reproductoras de objetos ideales". ${ }^{43}$

E 11,21 (H 15,9; C 22,4)

$M$ (2) $P$ (2) El sujeto de una predicación falsa ino es objeto s.l.?

E 11,30 (H 14,34n; C 21,34)

$M$ Soberbia 
E 13,1 (H 16,23; C 23,20)

$M$ (1) $P(1)$ ¿Hay realmente "fantasear" de lo psíquico?

E 13,6 (H 16,28; C 23,25)

$M \mathrm{NB}$

E 13,18 (H 17,6; C 23,36)

$M$ (2) $P$ (2) Cap. No habría conocimiento de más esencias que las de objetos dados en algún caso en la experiencia s.l., al menos en sus componentes. 45,3 «= cuarto párrafo del $\S 25$.»

En el tercer párrafo de la página 45 Gaos subrayó las palabras "reine Wesenszusammenhänge ohne die leiseste Mitsetzung von Erfahrungstatsachen", que en apariencia expresan una afirmación opuesta a la de su anotación.

E 15,3 (H 18,39; C 25,38)

$M$ (1) $P$ (1) Parece tratarse de las esencias de los individuos en cuanto esencias y en cuanto de los individuos.

E 16,22-26 (H 20,22-25; C 27,25-28)

$M !$ «El signo de admiración abarca las cinco líneas.»

E 23,19-20 (H 28,9-10; C 35,9-10)

$M$ ? «El signo de interrogación abarca las dos líneas.»

Gaos dedica varias páginas de sus obras-cursos a discutir la distinción de que aquí se trata entre conceptos categoriales y esencias categoriales y otras análogas o relacionadas con ella. Véase principalmente la lección IV de la segunda parte de De la filosofía, OC XII, p. 244.

E 32,37-39 (H 38,34-35; C 45,31-33)

$M$ Fenomenología $\neq$ Eidética !?

Tal vez hasta su lectura de este volumen, Gaos consideraba —debido a cierta interpretación de las Investigaciones lógicas- que la fenomenología consistía principal o exclusivamente en lo que él llama "eidética"; 
es decir, que era, no una disciplina eidética entre otras posibles, sino en algún sentido la disciplina eidética única o la suprema o la que lo era por excelencia. Ya en su Introducción a la fenomenología (1929), y de modo mucho más explícito en La crítica del psicologismo (1929-1932), Gaos distingue dos partes en la fenomenología, una de las cuales es la "eidética". Esto sugiere que esta anotación no puede ser posterior a estas obras.

E 33,4-6 (H 39,4-6; C 46,4-6)

M La "Fenomenología eidética", de principio

E 33,11 (H 39,11; C 46,11-12)

$M$ Soberbia

E 36,17-27 (H 42,30-40; C 49,30-50,2)

$M$ «En letras grandes, que abarcan 3 ó 4 líneas cada una:» c $D$ a $D$ p

E 38,8 (H 44,28-29; C 51,29-30)

$M$ (1) $P$ (1) La cuestión sería si es la autofundamentación empírica o eidética la única posible sin contrasentido.

E 39,4 (H 45,28; C 52,32)

$M$ (1) $P$ (1) 1. Se percibe una percepción de algo. $D 2$. Se percibe que otras cosas no son percepciones-de-algo. $D$ 3. Se concluye que las cosas que no sean percepciones-de-algo no son percepciones-de-algo o que sólo una percepción-de-algo es una percepción-de-algo. Supra «Un signo de interrogación abarca los tres puntos anteriores. $Y$ una pequeña flecha apunta hacia arriba, a la parte superior de la página.» $R$ Todo se reduce a distinguir-agrupar cosas. ? Cf 106(4) «Remite a su propia anotación (4) de la página 106; véase abajo $\mathrm{E} 106,32 . »$

E 39,20 (H 46,9-10; C 53,10)

$M$ cap 
E 40,14 (H 47,7; C 54,10)

$M$ (1) «Y en letras muy grandes:» cap $P$ (1) Todo (él) reposa (v. aparte final) en la idea de que lo ideal, absolutamente único e intemporal, no puede ser producto psíquico ${ }^{(a)}$ : esta es la cuestión. «Las palabras esta es la cuestión tienen aproximadamente el doble de tamaño que el resto.» (a) Petición de principio!

La apretada inserción de la nota introducida con la llamada "(a)" indica seguramente que se trata de una anotación posterior. La "cuestión" aludida, que para Gaos se revela en última instancia como una antinomia, es discutida por extenso en De la filosofía $a^{44}$ y Del hombre $e^{45}$ y tiene, además, una relación innegable con el punto central de su crítica a la crítica de Husserl al psicologismo. ${ }^{46}$

E 40,16-19 (H 47,9-12; C 54,12-15)

$M$ (No) identidad de realidad s.l. y s.e. $D$ (La cuestión!)

E 40,37 (H 47,35n; C 54,35n)

M Soberbia

E 42,3-9 (H 49,1-7; C 56,9-17)

$M$ «En letras grandes:» $c D$ a $D$ p

E 42,4 (H 49,2; C 56,11)

$M$ (1) $P$ (1) Sí, pero el hecho es que los formamos.

E 42,12 (H 49,10; C 56,21)

$M$ (2) $P$ (2) La cuestión es si la identidad-unicidad ${ }^{(a)}$ de cada objeto ideado-ideal requiere su exterioridad-trascendencia a lo psíquico. $D$ (a) La intemporalidad es reducible a ella. «En la esquina inferior derecha, al lado de las últimas líneas de esta anotación, con letras grandes, encerradas en un cuadro y muy repasadas:» cap

Hua IIl/2, p. 482: H 49,2-5. 
E 42,13 (H 49,11; C 56,22)

M 109 (3) «Remite a la página 109, anotación (3); véase abajo: E 109,30.»

E 44,2 (H 51,9; C 58,21)

$M$ (1) P (1) La intuición da una distinción entre objetos, pero no que sea entre objetos psíquicos y no-psíquicos; puede ser entre psíquicos concretos y abstractos.

Aparentemente, se refiere todavía a la cuestión de la diferenciación entre lo ideal y lo psíquico, ahora en vista del "principio de todos los principios", que Husserl acaba de establecer en el texto. Cuáles pudieran ser esos objetos "psíquicos abstractos", lo ignoramos. Tal vez se refiere Gaos a los que llama "pensamientos", cuyo "carácter abstracto" dilucida en De la filosofía. ${ }^{47}$

E 49,41 (H 58,7; C 66,3)

$M$ (1) $P$ (1) También en el tiempo? No se va hacia el pasado o el futuro como hacia allí.

E 51,33 (H 60,6; C 68,2)

M 115 (1) «Remite a página 115, anotación (1). Véase abajo: E 115,23.»

E 52,40 (H 61,18; C 69,19)

M 86 (1) «Remite a página 86, anotación (1). Véase abajo: E 86,31.»

E 53,40 (H 62,23-24; C 70,25)

$M$ (1) $P$ (1) "Ganz anderem", pues?

Las palabras ganz anderem (muy distinto en la traducción de Gaos) se encuentran un par de líneas arriba (H 62,21-22).

E 55,31 (H 64,18; C 72,21)

$M$ cap 
E 56,29-30 (H 65,20-21; C 73,23-24)

M 86 (1) «Remite a página 86, anotación (1). Véase abajo: E 86, 31.»

E 59,1-5 (H 68,5-9; C 76,9-13)

$M$ (Eidética de la conciencia y Fenomenología de la conciencia)

E 59,16-18 (H 68,21-22; C 76,23-25)

$M$ (Fenomenología = de la conciencia) «Una raya extiende el paréntesis hasta la línea 22 (en H hasta la 26; en C hasta la 29).»

E 59 (H 68,5-69,7; C 76,9-77,9)

$P$ El presunto gran descubrimiento de la Fenomenología es a lo sumo una nueva formulación de la reestructuración idealista "empírica" o "subjetiva"!

En relación con esta anotación, y con otras que también tienen como tema el idealismo, tómese en cuenta que, dentro del antinomismo de Gaos, la antinomia radical es la que hay entre el realismo y el idealismo trascendental, y que el idealismo consecuente es solamente el trascendental, no el empírico, en sentidos afines, aunque no del todo idénticos, a los empleados por Husserl. ${ }^{48}$ Pero aparentemente, durante esta lectura de Ideas I Gaos no teinía aún tipificado el idealismo de Husserl como trascendental.

E 60,9-10 (H 69,15-16; C 77,16-17)

$M$ Eidética de la conciencia

E 61,16-17 (H 70,26-27; C 78,28-29)

$M$ Eidética de las vivencias

E 73,32 (H 84,9; C 92,10)

$M$ Aporía

b Hua Ill/2, p. 486: H 68 (también en relación con la nota anterior). 
E 76 (H 86,24-87,29; C 94,23-95,29)

$P$ Lo recordado es trascendente

Lo intrafeccionado en el tiempo

«Un signo de interrogación abraza las tres líneas.»

E 76-77 (H 86,24-88,34; C 94,23-96,35)

$R$ Cosa $=$ realidad s.e. "Tres llamadas numeradas remiten a sendos lugares:

E 76,21-22 (H 87,9; C 95,7-8), E 77,1-2 (H 87,29-30; C 95,29-30) y E 77,8 (H 88,1-2; C 96,2).»

E 77,14 (H 88,8; C 96,8)

$M$ (1) $P$ (1) Paradoja:

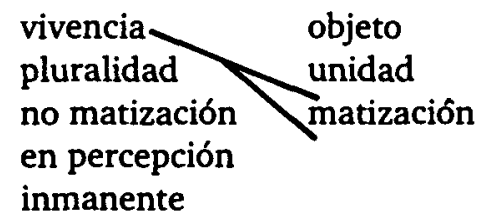

E 77,31-32,36-37 (H 88,25-26,31-32; C 96,26-27,31-32)

$M$ (2) $P$ (2) 2 sentidos de "aparecer" «Aquí un símbolo ilegible." $D$ 1) la cosa física (espacio1) $72 ~ «=90-91$ de $C . » D$ en el fenómeno (espacio2) $D$ 2) éste $D$ en los matices

Todo parece indicar que por "espacio1" (espacio en primer sentido) debe entenderse el presunto "espacio objetivo" (objektives Raum) de la física, del que Husserl habla en E 72 (H 82-3; C 90-1); el "espacio2" sería en cambio el "espacio natural de los sentidos" (natürlichen Sinnenraum), el "espacio del mundo de lo percibido en persona" (Raum der leibhaften Wahrnehmungswelt) -al que también se refiere en esas páginas.

E 82,37 (H 94,8; C 102,12) ${ }^{\mathrm{c}}$

$M$ (1) $P$ (1) El absolutismo de las vivencias es expresión de su temporalidad: "momentaneidad" irrepetible!

$\begin{array}{lll}2^{\mathrm{a}} \text { paradoja: } & \text { vivencia } & \text { cosa } \\ & \text { pluralidad } & \text { unidad } \\ & \text { unicidad temporal } & \text { pluralidad intuitiva }\end{array}$

c Hua IIl/2, p. 495: H 94,8. 
Los conceptos de "momentaneidad" e "intermomentaneidad" son importantes en el pensamiento de Gaos. La momentaneidad de la filosofía (determinada por la de la vida del sujeto que la hace y que a la vez es objeto de ella) es uno de los factores de su misma subjetividad y por ende una de las razones por las cuales no puede erigirse en ciencia objetiva (intersubjetiva, intermomentánea) y por las que está condenada a ser un saber histórico, biográfico, personal. ${ }^{49}$

\section{E 82,21 (H 93,31; C 101,35)}

$M(2) R(2)$ Intuición inmanente $\varangle$ apercepción(es)

\section{E 85,3 (H 96,22; C 104,29)}

$M(1) P(1)=$ la perceptibilidad de Stuart Mill!

\section{E 86,31 (H 98,16; C 106,27)}

$M$ (1) $P$ (1) La tesis general < la atesis «?» de particulares $52 / 3$ «= segundo párrafo del § 30 . Véase arriba: E 52,40.»

La limitación de la epoché < la tesis general 56,4 y $5 \ll=$ tercero $y$ cuarto párrafos del § 32. Véase arriba: E 56,29-30.»

párrafo ( $y$ ss.) del § 33.»

$\Varangle$ la conciencia pura 57,3 ss $\ll=$ primer

De la epoché de la tesis general a la incertidumbre del mundo: contradicción entre 56,5 y 87,2 «= penúltimo párrafo del $\S 46 . »$ Cf 88,2 «= segundo párrafo del $\S 47 . »$ pp «?» «Debajo de la incertidumbre:»e innecesidad

\section{E 86,35 (H 98,20; C 106,30)}

$M(2) R(2)$ Vivencia dada de hecho no puede no ser - pero no es más que de hecho, no necesariamente, como concluye $92 \backsim=\mathrm{H} 104,12-105,16 ; \mathrm{C}$ 112,35-113,última línea.»! «El signo de admiración abarca las dos líneas en que consiste esta anotación.»

E 87,24-26 (H 99,17-20; C 107,25-27)

$M$ Ejemplo del vaivén entre conciencia y conciencia pura 
E 87,31-34 (H 99,25-28; C 108,4-8)

$M$ [Posibilidad del idealismo berkeleyano]

E 90 (H 102,1-103,5; C 110,15-111,28)

$P$ El sociologismo de lo ideal funda su universalidad en la inter-subjetividad. Por qué no un análogo inter-subjetivismo de lo real, sino que aquí la intersubjetividad se toma por objetividad?

E 91,7-8 (H 103,13-14; C 111,36-112,1)

$M$ (1) $P(1)$ Husserl parece aquí cartesiano, berkeleyano, prekantiano, ingenuo, comparado con kantismo y neokantismo. «La sola posición de la llamada no indica si lo que Gaos afirma se quiere aplicar a algo dicho por Husserl en el $\S 48$ o en el § 49."

E 92,13 (H 104,24-25; C 113,10)

$M$ (1) (2) $P$ (1) La no necesidad del mundo para la conciencia $\neq$ la necesidad de la conciencia: ésta es tan no necesaria como el mundo y su necesidad necesitaría de un ser necesario! si no realis, real. Claro que Husserl pone entre comillas "re", pero si tomase en serio esta restricción, no podría tomar en serio el "absoluto": éste implica que fuera de la conciencia no habria más que "res". $R$ (2) Cartesianismo: lo pensable independiente $=$ independiente en realidad. «Encima de pensable:» esencial «Debajo de realidad:» existencia $96 «=$ última parte del único párrafo del $\S 51$ antes de la "nota". El texto de la nota (1) abarca en realidad todo el margen inferior de las páginas 92 y 93.»

E 92,17 (H 104,29; C 113,14)

$M(3) R(3)$ Experimentabilidad ( $88 s s) ~ «=\S 47 . » \neq$ dependencia real!

E 93,24-31 (H 106,1-8; C 114,27-35)

$M$ Remisión del mundo (extensión de la [teoría] sobre él al yo [«palabra ilegible, acaso impuro']) a la conciencia: de la imposibilidad de la inexistencia a la dependencia real (4) $D \downarrow R$ (4) Tal imposibilidad $\neq$

d Hua III/2, pp. 497-498: H 102 y 103.

c Hua IIl/2, p. 499: H 106. 
dependencia real! «La flecha hacia abajo que se encuentra bajo la llamada (4) apunta, aparentemente, hacia la anotación que sigue: (5).»

\section{E 93,7-10 (H 105,23-26; C 114,9-12)}

$M$ «Al lado de la punta de una llave que abraza las 4 líneas:" (5) $P$ (5) Del absoluto de la percepción sin apercepción (81) «= tercer párrafo del $\S 44$.» al de la existencia independiente de otra

\section{E 98,15-16 (H 111,11-12; C 120,14-15)}

$M$ (1) $P$ (1) Petición de principio. 84/5, 88/9 «O sea, páginas 84 y 85,88 y 89 de E: H 95,15-97,23 y 99,29-102,1, y C 103,19-105,33 y 108,8110,15 . Las afirmaciones claves se encuentran en el último párrafo del $\S 45$ y en el segundo párrafo del $\S 47$, respectivamente.»

\section{E 101,33 (H 114,39; C 124,2)}

$M$ (1) «Esta llamada se encuentra dentro de una anotación descriptiva (grupo 1), toda ella entre paréntesis."

$P(1)$ En todo esto juega la confusión de

"realidad"

fenómeno 1

fenómeno 2

conciencia.

En este caso, no es que Gaos le atribuya la confusión a Husserl. Por el contrario, simplemente enlista los términos entre los que se da la confusión que Husserl expone en el texto. Si entendemos bien la nomenclatura de Gaos (que usa también en otras anotaciones no transcritas y aparentemente de un modo no uniforme), "fenómeno1" = "apariencias sensibles" (sinnlichen Erscheinungen), es decir, "los objetos que aparecen en cuanto tales"; "fenómeno2" = "vivencias del aparecer" (Erlebnissen des Erscheinens); "'realidad'" = el supuesto ser físico "objetivo" postulado para "explicar" causalmente las apariencias. ${ }^{50}$

\section{E 102,25 (H 115,32; C 124,38)}

$M$ (1) $P(1)$ Pero lo cierto es que los modelos las hacian intuitivas. Husserl confunde la (falsa) imposibilidad de hacer intuitivo lo conceptual y 
la (sostenida por él) imposibilidad de conocer ni intuitiva ni conceptualmente la "realidad".

Sobre este término de "'realidad" ", véase mi comentario a la anotación anterior.

E 103,1-8 (H 116,9-16; C 125,18-24)

$M$ [Aporía] de la conciencia pura y las conciencias impuras $D$ (1)

$P$ (1) En rigor, habría que examinar todas estas relaciones:

conciencia(s) propia impura(s) pura(s)

ajena(s)

E 103,16-21 (H 116,24-29; C 125,32-37)

$M$ y solución (?) por la apercepción "fundada" en el cuerpo

E 105,5 (H 118,20; C 127,28)

$M$ (1) $P$ (1) Qué penosa descripción de la reestructuración de la visión del mundo realista en la idealista.

E 106,9,26 (H 119,28,120,9; C 128,32-33,129,14-15) ${ }^{\mathrm{i}}$

$M(1) P(1)$ No está aún claro si la vivencia absoluta es la que es objeto de la de reflexión en cuanto objeto de ésta o ésta, la de reflexión.

E 106,7,23 (H 119,25-26,120,6; C 128,31,129,12)

$M$ (2) $P$ (2) Husserl cree que la reestructuración de la visión realista en la idealista ${ }^{(a)}$ no es Metafísica porque ${ }^{(b)}$ es factible sin poner nada metafenoménico - más bien, dejando de poner lo metafenoménico del realismo no ingenuo. $Y$ tiene razón en (b), pero no en (a), si resultase que la Metafísica se reduce a reestructuraciones como ésta.

E 106,22 (H 120,5; C 129,10)

$M$ (3) $R$ (3) Quiere decir que da a cada una su sentido o que da a todas el de realidad, en el de infra "Zieht man", etc.?

8 Hua III/2, p. 501: H 116,13.

h Hua Ill/2, p. 501: H 118,16-20.

i Hua IIl/2, p. 502: H 120,9. 
Se refiere a la frase que comienza "Zieht man den Begriff der Realität..." (en su traducción: "Si se saca el concepto de la realidad...") cinco líneas más abajo.

E 106,32 (H 120,15; C 129,21)

$M(4) R$ (4) Aquí se ve muy bien en qué estriba la Eidética: dado a un término un sentido - "Zieht man", etc.— no cabe dejar de dárselo!

E 107,1 (H 120,24; C 129,30)

$M$ Soberbia

E 108,3 (H 121,26; C 130,35)

$M$ (1) $P$ (1) Como si lo último no implicara lo anterior!

E 109,2-4 (H 123,2-4; C 132,7-10)

$M$ La cuestión de la reducción del yo puro «A la derecha de esta anotación:» (a) $R$ (a) Sólo pudo ocurrirse plantearla en vista de la trascendencia del yo puro a las vivencias.

E 109,9 (H 123,10; C 132,15)

$M$ (1) P (1) No está claro si el "cogitatio" y el "cogito" se refieren al acto objeto del de reflexión, a éste, a los dos. .. Nueva manifestación del no estar claro cuál sea la conciencia pura, si la que reflexiona o la que es objeto de ésta.

E 109,27 (H 123,27; C 132,33)

$M$ (2) $P$ (2) Nuevo ejemplo de la tendencia a tomar lo permanente por necesario.

E 109,30 (H 123,30; C 132,37)

$M$ (3) P (3) El fenómeno es como el que impuso la idealidad.

E 110,2-4 (H 124,5-7; C 133,12-14)

$M$ (1) $D$ Solución de la cuestión $P(1)$ Pero si toda trascendencia era de alguna manera en la inmanencia! 


\section{E 110,5 (H 124,8; C 133,15)}

$M(2) P(2)=$ en lo que tiene de puro no es reducible; simplemente no toda fenomenología de vivencias requiere la de él.

\section{E 111,11 (H 125,16; C 134,24)}

$M$ (3) $R$ (3) No quiere decir que requiera una razón el hecho absoluto de la conciencia pura, sino simplemente la teleologia de su objeto intencional y de sus vivencias correlativas de éste. Un hecho absoluto $=$ necesario ( $91 \mathrm{ss)} "=\S 49 . »$ ino, contradictio in adiecto? «La anotación propiamente dicha se encuentra en la página 110.»

\section{E 111,13 (H 125,19; C 134,26)}

$M(1) P(1)$ Todo esto especifica la teleología de $96 \mathrm{~s}$.

\section{E 111,26 (H 125,31; C 134,39)}

$M$ (2) $P$ (2) Como si una conciencia absoluta y un Dios, absoluto naturalmente, fuesen conciliables de otro modo que identificándolos, lo que plantea el problema de la trascendencia de algo a aquello con lo que es idéntico. Esto hubiera $R$ debido ser bastante para hacerle a Husserl ver cuando menos un momento como problemático el absolutismo de su conciencia pura. Pero tenía la "evidencia" de la "estructuración idealista" (que es la forma más sutil de autodivinización)...

La autodivinización del filósofo, y en particular del idealista trascendental, es un corolario de su soberbia. El tema es recurrente en las obras de Gaos. ${ }^{51}$

\section{E 113,6-7 (H 127,19-20; C 136,28-29)}

$M$ (1) $P$ (1) Pero la Noética general no es ciencia de la ciencia deductiva exclusivamente. Las consideraciones metodológicas ulteriores ipueden justificarse como 113,2 ? «= el párrafo siguiente.» (3) $R$ (3) 133-2. «= último párrafo del $\S 71$. Aparentemente, ahi se encuentran las "consideraciones" a que se refiere la nota (1)."

\section{E 113,19-20 (H 127,32-33; C 137,1-2)}

$M$ (2) $P$ (2) Esto significa en rigor la no reducción de aquel mínimo de la Lógica formal s.l. ejemplificable en la conciencia pura. 117(1). «Anotación (1) de la página 117. Véase abajo: E 117,33.» 
E 114,11 (H 128,26; C 137,32)

$M$ (1) $P$ (1) Términos equívocos: todas las esencias son trascendentes $(113,3)$; las "inmanentes" son las trascendentes de las individualidades inmanentes (las vivencias). "Tras $(113,3)$, está insertado, encima de lo que sigue:» e inmanentes (todo lo es a la conciencia pura)! «Por lo demás, no resulta clara esa remisión a $(113,3)$.»

E 114,28 (H 129,5; C 138,13)

$M(2) R$ (2) Cuál es la relación de las esencias de las individualidades trascendentes reducidas con las de estas últimas sin reducir?

E 115,23 (H 130,3; C 139,10)

$M$ (1) $P$ (1) La reestructuración idealista se fundaría, pues, en la actitud natural y no en las eidéticas. Qué pensar de este suponer éstas aquélla en relación con $51,2 f$ ? «= último párrafo del § 28.»

E 116,1-2 (H 130,21-22; C 139,30-31)

$M(1) P(1)$ Reducción eidética $\neq$ reducción fenomenológica!

E 116,33 (H 131,17; C 140,25)

$M$ (2) $P$ (2) La Eidética sería, pues, para la reducción de lo eidético trascendente s.e.

\section{E 117,33 (H 132,19; C 141,26)}

$M$ (1) $P$ (1) Si quiere decir que la Fenomenología no debe contar con la idealidad de lo ideal trascendente, ¿cómo puede contar con la de lo inmanente? ¿como en 113,2? «Véase arriba: E 113,6-7. Lo siguiente está escrito en letras de mayor tamaño.» La anteposición de la Eidética significa ni haberse planteado los problemas radicales de la relación $R$ entre conciencia pura y eidética: $D$ conciencia pura «y ligeramente separado:» esencias $D$ inmanentes trascendentes

Gaos vio siempre, o intentó ver siempre, un vínculo (¿esencial?) o una dependencia entre la reducción eidética y la reducción fenomenológica, y correlativamente también entre las esencias y la conciencia pura; un vínculo, en todo caso, que no se encuentra, hasta donde sé, en las obras de Husserl. ${ }^{52}$ 
E 119,27 (H 134,23; C 143,33)

$M(1) P(1)$ Aun en las Meditaciones es la Fenomenología desde el principio eidética, aunque sólo en el curso de ella se haga tema de la Eidética.

Se trata sin duda de las Meditaciones cartesianas (lo cual indica que esta anotación es posterior a la publicación de esa obra (1931)).

E 122,20 (H 137,31; C 147,31)

$M$ (1) $P$ (1) Cuál es la relación entre el fenomenólogo, que no entra en las proposiciones, y el yo puro, que entra en ellas? Cf 127,2ff! «Esta referencia no resulta clara. A la izquierda de la anotación, con letras de mayor tamaño:» c $D$ a $D$ p

E 124,10 (H 139,29; C 149,32)

$M$ (1) $P$ (1) La Fenomenología principia (fenomenológicamente) a explicarse, aunque siempre en actos distintos de los explicados, cuya homogeneidad con éstos es un problema. . . El apoyarse en Psicología y Lógica no es lícito a la Fenomenología, ciencia de principio: ella debe resolver el problema para sí y las demás.

E 129,12-15 (H 145,11-13; C 155,13-15)

$M$ Halo de determinabilidad indeterminada $D$ (1) $P$ (1) Mejor: indeterminación determinable. Caso del abstractivismo del alemán.

En C, Gaos traduce la expresión en cuestión ("Hof von unbestimmter Bestimmbarkeit"), que literalmente sería "halo de determinabilidad indeterminada", como "halo de indeterminación susceptible de determinación".

E 146,10 (H 163,38-39; C 174,6-7)

$M$ (1) $P$ (1) Confusión reducciones fenomenológica y eidética $147 \mathrm{pp}$ «?, quizá se refiere a los dos penúltimos párrafos del $\S 77 . » D$ 152,1 «= segunda mitad del primer párrafo del $\S 79 . » ; 153,3 ~ «=$ quinto párrafo del $\S 79 . »$

E 149,33 (H 167,32; C 178,12)

$M$ Impresiones (1) $P$ (1) Humismo. 
E 160,12 (H 179,8-9; C 189,26-27)

$M(1) P(1) ¿ Q u e ́$ diferencia entre "abstenerse" en la actitud natural y la abstención fenomenológica? ¿Es ésta aplicable realmente a todo lo de la actitud natural?

E 160,18 (H 179,14; C 189,33)

$M(2) R$ (2) Esencia = en el hecho mismo, "concreta". Cf. 162 (1). "Remite a su anotación (1) de la página 162 (que es la siguiente), la cual remite a su vez a ésta.»

E 162,11 (H 181,14; C 191,32) j

$M(1) R(1)$ Cf 160 (2)

E $163,15,32$ (H 182,22,183,3; C 193,8,26)

$M$ (1) $P$ (1) Ej. del método.

E 163,22-23 (H 182,28-29; C 193,16-17)

$M$ ?!!!

La interrogación y la admiración se refieren, sin duda, a la frase "Aber der Erlebnisstrom kann nicht anfangen und enden." (en la traducción de Gaos: "Pero la corriente de las vivencias no puede empezar ni finalizar.").

E 164,27 (H 183,36; C 194,21)

$M$ (1) $P$ (1) Los tres momentos están vistos confusamente como móviles y estáticos, contenidos y forma.

Se refiere, claro, a los momentos del ahora, el antes y el después.

E 164,28 (H 184,1; C 194,23)

$M$ (2) P (2) La sucesión de las vivencias implicaría de suyo reflexión; cf. 165,2 ? «= segundo párrafo del § 82.»

j Hua III/2, p. 505: H 181,13-28. 
E 165,11-13 (H 184,24-26; C 195,9-11)

$M$ NB «Escrito en letras que abarcan las tres líneas.»

E 172,7 (H 192,11; C 203,3)

$M$ (1) P (1) Qué "datos"!

E 176,9 (H 196,24; C 207,14)

$M(1) P(1)$ Kantismo + Psicología.

E 177,39 (H 198,22; C 209,13)

$M$ (1) $P$ (1) El eidetismo = fijación de lo empírico. $D$ El idealismo = interpretación de la correlación Empírica como inherencia metafísica.

E 180,23-25 (H 201,25-28; C 212,12-14)

$M$ Validez universal de la Fenomenología (1) $P$ (1) Su congruencia con el solipsismo de la conciencia absoluta, problema ni planteado.

E 184,15 (H 205,29; C 216,17-18)

$M(1) P(1)$ Las tiene con distinto signo!

E 184,22-23 (H 205,37-38; C 216,25-26)

$M$ iel nóema $D$ (2) $P$ (2) Luego éste no significa el objeto en cuanto tal, sino en general!

E 184,31-32 (H 206,8-9; C 216,34-35) ${ }^{\mathrm{k}}$

$M$ "en cuanto tal" $D(3) P(3)$ Luego "en cuanto tal" no es correlativo a la actitud fenomenológica, sino ya a la psicológica!

E 187 (H 208,25-209,29; C 219,16-220,20)

$P$ Cambio de signo u objetos ideales?

k Hua III/2, p. 507: H 206,5. 
E 187,1 (H 208,25; C 219,16)

$M$ Esencia de la reducción fenomenológica

E 228 (H 254,1-255,2; C 265,1-26)

$P$ (Potencial $<$ inatención $\rightarrow$ actual $^{1}<$ atención) $\left[\leftarrow\right.$ actual $^{2}=$ ponente $\left.^{2}\right]$ ponente $^{2} \quad$ †neutralizado

(Dirección de la mirada $\neq$ poner o no poner) $=$ cap para el idealismo $=$ "idealización" (epoché) de todo.

E 232,7 (H 258,16; C 269,10)

$M$ (1) $P$ (1) En este parágrafo funcionan las modificaciones de neutralidad y de fantasía como si fuesen una.

E 233 (H 259,16-260,21; C 270,9-271,12) ${ }^{\mathrm{m}}$

$P$ Epoché

$\rightarrow$ nóema

$\wedge$

epoché $=$ modificación de neutralidad $\rightarrow$ contranóema

E 235,35 (H 262,21; C 273,14)

$M$ (1) $P$ (1) Antes (cf 228 infra) «= cuarto párrafo del $\S 113 . »:$ potencialidad - actualidad ponente neutra

Ahora: $\quad$ potencialidad - actualidad

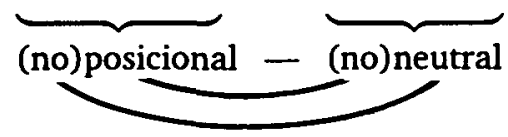

E 241,38-40 (H 269,12-14; C 280,13-15)

$M$ Las clasificaciones de los fenómenos psíquicos = de posiciones (1) $P$

(1) Piensa en la de Brentano.

1 Hua III/2, p. 510: H 254,1.

m Hua III/2, p. 511: H 259,19-24.

n Hua III/2, p. 512: H 269,14. 
E 242 (H 269,15-270,18; C 280,16-281,17) ${ }^{\circ}$

$P$ Tesis $=$ a) posicionalidad y posición actual de b) $\left\{\begin{array}{l}\text { la representación } \\ \text { el ánimo }\end{array}\right.$ tesis neutralizadas = insusceptibles de posición actual (lo que implicaría que dentro de la neutralización no habría distinción entre posicionalidad y posición actual!) (1) $R$ (1) El concepto de neutralización oscila entre algo indiferente a potencialidad y actualidad y algo referente al paso de aquélla a ésta.

\section{NOTAS}

1. Edmund Husserl, Ideen zu einer reinen Phänomenologie und phänomenologischen Philosophie, Erstes Buch: Allgemeine Einführung in die Phänomenologie. 3. unveränderter Abdruck. (Sonderdruck aus: "Jahrbuch für Philosophie und phänomenologische Forschung", Bd. I herausgegeben von E. Husserl-Göttingen.) Halle a.d.S., Verlag von Max Niemeyer, 1928.

2. La primera edición de la traducción de Gaos se publicó en 1949: Ideas relativas a una fenomenología pura y una filosofía fenomenológica, Fondo de Cultura Económica, México. Ni en la portada ni en la portadilla del volumen se indica que se trata solamente del primer libro de la obra, aunque el título "Libro primero: Introducción general a la fenomenología pura" aparece en el lugar que le corresponde, al final de la introducción. La traducción no fue hecha sobre la edición de Walter Biemel de 1950 (Hua III, Martinus Nijhoff, La Haya) y no incluye, por tanto, los apéndices que aparecieron en ésta ni contempla las anotaciones de Husserl y demás materiales que Biemel empleó para refundir el texto. Pero para la segunda edición, de 1962, Gaos añadió la traducción de esos apéndices, así como la del "Prólogo a la edición alemana de 1950" de Biemel, y aunque mantuvo intacto el texto de la primera edición, incluyó aquellos materiales en el "Apéndice crítico" - tomado de la eđición de Biemel-, insertando en el texto las llamadas correspondientes (véase la nota entre corchetes de la p. 446, en la que se explica esta circunstancia). En 1986 apareció una tercera edición que no difiere de la segunda en nada significativo. Por otro lado, desde la primera edición aparece el "Epllogo" (traducción del "Nachwort zu meinen Ideen" de Husserl, publicado por vez primera en 1930, en el tomo XI del "Jahrbuch für Philosophie und phänomenologische Forschung", por Niemeyer, Halle, y más tarde en $H u a \mathrm{~V}, 1952$ ), el cual se presenta sin ninguna advertencia particular - fuera de la que el mismo Husserl hace en las primeras líneas. Resulta curioso constatar, pues, que a partir de su segunda edición la traducción de Gaos está en realidad basada en tres publicaciones diferentes: el cuerpo de la obra, así como el índice analítico elaborado por Ludwig Landgrebe, proceden de una de las tres ediciones de Max Niemeyer (1913, 1922 y 1928) hechas en vida de Husserl, y

- Hua IIl/2, p. 512: H 269,20 y 22f; y H 270,15. 
con casi total seguridad de la tercera (acaso de E, al menos en parte); todo el aparato crítico, incluyendo el prólogo y los apéndices, proceden de la edición de Biemel de 1950; por su parte, el epllogo procede de la primera edición del "Nachwort" que mencioné hace un momento. De todo lo cual el lector no recibe más que muy escasa noticia: la única aclaración que hace Gaos explícitamente se halla en la nota de la p. 446 a la que ya me referf. (Como es usual, abrevio en lo anterior y en lo siguiente Husserliana como Hua.)

3. Por ejemplo, el hecho de que las notas que llamo más adelante "de traducción" no sólo son relativamente muy escasas, sino que casi ninguna contiene el término o frase elegido en definitiva por Gaos.

4. De la filosofía, primera parte, lección XV, en Obras completas, vol. XII, 1982, p. 123. Las Obras completas de José Gaos, cuya edición coordina Fernando Salmerón, están en proceso de publicación por la UNAM dentro de la colección Nueva Biblioteca Mexicana. (En adelante abrevio las Obras completas de Gaos como OC.)

5. Más adelante se da una clasificación de las anotaciones y se aclara que las que aquí se transcriben son principalmente las que contienen comentarios de Gaos.

\section{Véase más adelante la nota 25 .}

7. La primera fue la de las Investigaciones lógicas, hecha en colaboración con Manuel García Morente y publicada en 1929 por Revista de Occidente (Madrid) en 4 tomos. Además de traducir la obra, Gaos hizo una "Explicación... de las Investigaciones parágrafo por parágrafo en dos cursos académicos" (OC, VII, UNAM, México, 1987, p. 365). En 1942 se publicó, por La Casa de España en México y dentro de la "Colección de textos clásicos de filosofía" del Centro de Estudios Filosóficos de la UNAM, su traducción de las Meditaciones cartesianas, hecha entre 1935 y 1936 sobre un texto que Ortega y Gasset recibió personalmente de Husserl en noviembre de 1934. En esta traducción faltaba la de la meditación quinta, que Gaos perdió cuando la tenía ya acabada aunque sin revisar. (Sobre esta traducción, el original en que se basó y la pérdida de la meditación quinta, pueden verse los siguientes textos de Gaos publicados en $O C$, VII: "Introducción a las 'Meditaciones cartesianas' de Husserl" (pp. 285-300), "Unas meditaciones de aventura" (pp. 329-334) y "Apéndice: Nota sobre la traducción de Husserl" (pp. 365-368); también la nota de Fernando Salmerón en el mismo volumen: "Nota del coordinador de la edición" (pp. 33-34), y, finalmente, la "Nota del editor", redactada por Miguel García-Baró, en la segunda edición, aumentada y revisada, de las Meditaciones cartesianas, Fondo de Cultura Económica, México, 1986, p. 8, así como su nota 3 al prólogo de Gaos en la misma edición, p. 31.) Véanse los datos de publicación de la versión de Gaos de Ideas I en la nota 2.

8. Véase la nota anterior. 
9. En esta fecha fue publicado, junto con el trabajo de tesis doctoral al que me refiero en seguida ("La crítica del psicologismo en Husserl"), por la Universidad Veracruzana: José Gaos, Introducción a la fenomenología, seguida de La crítica del psicologismo en Husserl, Cuadernos de la Facultad de Filosofía y Letras, no. 5, Universidad Veracruzana, Xalapa. (En adelante este volumen será designado como $I F$.)

10. Compárese, por ejemplo: "La fenomenología tiene aquellos caracteres que le prestan el ser ciencia eidética y el ser ciencia de la conciencia pura. Como ciencia eidética, las proposiciones que formula tienen el valor universal y necesario a priori que la intuición eidética confiere a las proposiciones que no hacen sino expresar fielmente sus datos. Como ciencia de la conciencia pura es la ciencia de lo absoluto y, por tanto, la primera y fundamental. Este es el rasgo idealista en la fenomenología de Husserl, que sus discípulos abandonan" (ibid.).

11. Véanse las notas 7 y 9 . En la nota 36 de su tesis (IF, p. 181), Gaos aclara: "Nuestro trabajo nos fue sugerido a principios del año 1927 por los profesores Morente y Zubiri. La exposición de la crítica de Husserl que constituye la primera parte se remonta en el modo de entender y presentar esta crítica a la labor realizada desde aquella fecha hasta mayo del siguiente año; la forma actual [... ], a una labor posterior, terminada a fines del año 1930 (en el número de enero-febrero de 1931 de la revista UNIVERSIDAD fue publicada la primera parte en su forma actual). Esta segunda parte de nuestro trabajo, la crítica de la crítica de Husserl, estaba esbozada al publicar a principios de 1931 la primera parte, como prueban los cuatro parágrafos preliminares; pero la forma en que aparece aqui es resultado de una labor dilatada hasta el final de 1932."

12. Página 20265 del manuscrito que contiene el proyecto del libro Jornadas filosóficas, manuscrito que forma parte del Fondo Documental de Gaos del Instituto de Investigaciones Filosóficas. Citada por Fernando Salmerón en "Jornadas filosóficas. La primera autobiografía de José Gaos", publicado en su libro Ensayos filosóficos, Secretaría de Educación Pública, 1988 (Lecturas mexicanas, 109), p. 242.

13. Nota 36 (al § 36) de La crítica del psicologismo en Husserl (en adelante $C P H$ ); $I F$, p. 181.

14. Gaos abunda: "El tomo I de las Investigaciones lógicas, las cuatro primeras de éstas - principalmente la segunda y tercera- y el capítulo de las Ideen sobre 'Tatsache und Wesen', favorecieron la interpretación de la fenomenología como ciencia universal y fundamental de las esencias, como ontología eidética, que es como llegó Scheler a identificarla con la 'prima filosofía', como ha sido desarrollada por el trabajo efectivo de muchos epígonos y como en general se la ha divulgado y combatido. [...] Pero las dos últimas Investigaciones lógicas y el cuerpo de las Ideen acentúan mucho más enérgicamente el otro elemento o factor de la fenomenologia, de tal suerte que si la fenomenología puede seguir teniendo los caracteres de la universalidad y la fundamentalidad, es merced a la concepción de la conciencia 
pura como el ser absoluto. [...] A esta concepción se atienen todavía más estrictamente las últimas publicaciones de Husserl, Formale und transzendentale Logik [... ] y Meditations cartésiennes. [... ], y a ella más que al elemento eidético, puede decirse abandonado, responde la última etapa de la fenomenología, representada por $M$. Heidegger [... ], de suerte que puede advertirse una como reacción conjunta de Husserl y Heidegger contra Scheler" (IF, p. 185).

15. José Gaos y Francisco Larroyo, Dos ideas de la filosofía (Pro y contra la filosofía de la filosofia), La Casa de España en México, Fondo de Cultura Económica, México, 1940. (En adelante, $D I$.)

16. DI, pp. 29-30. Véase también este pasaje del prólogo a su versión de las Meditaciones cartesianas: "El pasado entero de la filosofía puede reducirse a dos grandes movimientos sucesivos de dirección opuesta. La filosofía griega y con y tras ella la antigua y la medieval se han dirigido, como insinué antes, a los principios objetivos del mundo, en una ideación esencialmente eidética, añado ahora: concibiendo tales principios como ideas, valores, esencias subsistentes en sf y por sí, o inherentes a un principio divino, o concibiendo eidéticamente este principio. Radicalmente animada por el cristianismo, introductor decisivo de la conciencia, como instancia fundamental, en la historia, según revela la anticipación de San Agustín a Descartes, la filosofía moderna empezó por retrotraerse y retraerse reflexivamente a la conciencia, para partir de ella hacia el mundo y hasta los principios objetivos de éste y de ella. La tensión entre la eidética filosofía antigua y la conciencia cristiana en el seno de la filosofía medieval da a ésta su peculiar complexión y situación verdaderamente media, que no deja de prolongarse en su descendiente moderna. En la sucesión histórica de los dos movimientos, de la filosofía antigua y medieval y la filosofía moderna, debe reconocerse una sucesión promovida por una relación de fondo último entre ambos. Pues bien, ambos o el pasado entero de la filosofía vienen a ser asumidos notoriamente por las dos partes de la fenomenología de Husserl: la eidética filosofía antigua y medieval, el 'realismo' antiguo y medieval, en la 'fenomenología eidética'; la modema filosofía de la conciencia, el moderno 'idealismo', en la 'fenomenología trascendental'. Es más. La asunción de la filosofía llega al detalle de asumir la transición natural de todo 'idealismo' a un idealismo 'trascendental'. Por el lado, ya no del pasado y antecedentes de la fenomenología de Husserl, sino de su sucesión y futuro, de sus dos partes, también, han salido como he apuntado las principales filosofías posteriores a ella, que reiteran los dos grandes movimientos del pasado filosófico: el de la filosofía antigua y medieval, la filosofía de los objetos ideales y de los valores; el del cristianismo y la filosofía moderna, la filosofía existencial. En tales movimientos, asunciones y reiteraciones ¿cómo no palpar una encubierta, pero tangible naturaleza de la filosofía oscilante entre dos extremos dialécticamente unidos? Contenido y mérito últimos de la fenomenología de Husserl: la articulación de sus dos partes sugiere cuál podría ser la relación entre ambos movimientos de la historia de la filosofía, fondo último de esta historia entera y de la filosofía en general." ("Historia y significado", en Meditaciones cartesianas, 2a. ed., citada en nota 7, pp. 26-27; también en OC VII, pp. 296 s.) 
17. $D I$, pp. 75-77. Gaos concluye con un reproche y algo que quizá puede leerse como una humorada: "En fin, Husserl, que define y practica la filosofia como fenomenología, por una omisión e inconsecuencia, no insólita ni extraña en la historia de la filosofía - los filósofos han dejado a veces lo fundamental de su pensamiento, por ser precisamente lo fundamental menos patente para cada uno de ellos, a sus continuadores, a la historia ulterior de la filosofia, que así es como se desarrolla históricamente- se ha contentado con esta definición, sin haber hecho una expresa y rigurosa fenomenología de la filosofia. Acaso, de haberla hecho, hubiera concluído que este fenómeno humano que es la filosofia, es confesión personal." (DI, p. 77.)

18. Véase el "Prólogo" de Fernando Salmerón en OC XIII, p. 17. Este prólogo fue publicado también en Diánoia. Anuario de Filosofía, vol. XXXVI, 1990, pp. 1-16, con el título "Introducción a la filosofía de Gaos". Hay que remitirse a él en relación con el tema del pensamiento de Gaos en general, que aquí sólo toco marginalmente, y con el de la filosofía expuesta en estas obras claves. Pueden verse también los otros escritos de Salmerón a los que él mismo remite en la nota 19 de este prólogo: "La ontología de José Gaos", en Cátedra, no. 2, Universidad Autónoma de Nuevo León, Monterrey, enero-marzo de 1975; y "La naturaleza humana y la razón de ser de la filosofia. La estructura de De la filosofia de José Gaos", en Diánoia, no. 20, México, 1971. También es importante el "Prólogo" de Luis Villoro al tomo XII de OC, que contiene De la filosofia.

19. Cfr. la lección I de la primera parte, $O C$ XII, p. 3.

20. OC XIII, p. 39. También en otros pasajes de sus obras alude Gaos a diversas investigaciones fenomenológicas o "fenomenologías" posibles; a modo de ejemplo, en OC XVII, p. 126: "Hubo un momento, lato sensu, en que me pareció que la decepción filosófica procedía de determinada incompatibilidad entre la esencia de la Filosofía y la 'esencia' de la vida contemporánea: la Filosofía de la Filosofía requería la determinación de esta última 'esencia', partiendo de una 'fenomenología' de la vida contemporánea."

21. Aunque sí da sus razones, en la primera lección, exposición del curso entero, para que "la Filosofía, principie, para mí, por la Fenomenología de la Expresión Verbal $\longrightarrow$ de que ésta acabe, para mí, por ser la Filosofía de la Filosofía entera y, o, la Filosofia" (OC XII, pp. 6 s.).

22. OC XIII, p. 39. Lo que a esto sigue no lo aclara mayormente: "Este método fenomenológico, en cuanto aplicado a fenómenos de expresión, requiere una comprensión de las expresiones, o de lo expresado por ellas, que hace de él un método hermenéutico" (ibid.).

23. Acaso sirva también como orientación la referencia que hace Gaos al método fenomenológico en otro contexto: "el método considerado como el método por excelencia para describir o caracterizar y definir esencias por la filosofia de nuestros 
días: el método de la fenomenología eidética. No el método fenomenológico en el sentido riguroso de la fenomenología de Husserl: el método de la ciencia eidéticotrascendental de las esencias de los fenómenos puros de la conciencia pura; sino el método fenomenológico en el sentido más laxo y lato que se generalizó en torno a la estricta ortodoxia husserliana, desde el interior de la escuela misma de Husserl hasta lontananzas en las que se trata pura y simplemente de descripciones de cualesquiera objetos, dirigidas por una vaga intuición de lo esencial de éstos, no garantizadas por nada susceptible de verificación objetiva o intersubjetiva, tan sólo conducidas en algún orden 'metódico'." (José Gaos, En torno a la filosofia mexicana, Alianza Editorial Mexicana, México, 1980 (Biblioteca Iberoamericana), p. 84.)

24. Véase, en efecto, cómo comienza la lección II de la primera parte de De la filosofia, auténtico inicio del curso: "El método fenomenológico prescribe partir de expresiones verbales designantes del objeto del que se quiere hacer la fenomenología y de un ejemplo o ejemplar de tal objeto. Nosotros debemos ahora hacer la fenomenología de la expresión verbal. Como expresión verbal designante de la expresión verbal puede bastar por lo pronto esta misma expresión verbal: 'la expresión verbal'. Partamos, pues, de un ejemplo de ella. Sea la expresión verbal 'esta sala'." (OC XII, p. 11.) Paralelamente, la lección II de Del hombre comienza: "La primera gran regla del método fenomenológico es la de partir de las expresiones verbales designantes del fenómeno del que se trata de hacer la fenomenología, para elegir un caso o ejemplar individual o específico, percibido o recordado o imaginado, del fenómeno designado por ellas que lo sean inconcusamente, y proceder al análisis descriptivo, conceptual y terminológico, del caso o ejemplar bajo el punto de vista de lo que sea, con evidencia intelectual, esencial a él o al fenómeno." (OC XIII, p. 43.)

25. Confesiones profesionales, OC XVII, p. 59. Tras relatar cómo Xavier Zubiri le explicó una tarde "la fenomenología entera", dice Gaos: "También, pues, para Zubiri parecía no haber más que la fenomenología. Su tesis iba a ser un ensayo de una teoría fenomenológica del juicio. Y él era el prodigio - y el bien enterado: era ya graduado de Roma y había estado ya en Bélgica y en Alemania. Decididamente, la fenomenología de Husserl era la filosofía" (p. 62). Y un poco más adelante, agrega: "En su Kant dice Ortega que la filosofía kantiana fue su prisión durante aproximadamente diez años. La de Husserl, su maestro Brentano, el inspirador de ambos, Bolzano, y algunos discípulos inmediatos de Husserl, el mayor Scheler... fue mi prisión durante también aproximadamente diez años: de 1923, en que me licencié, pasando por 1928, en que me doctoré con una tesis sobre el tema dicho, e hice mis primeras oposiciones a cátedra, hasta 1933" (ibid.).

26. Recapitulando, Gaos afirma: "En suma, que he vivido como la verdad, por lo menos, la escolástica de Balmes, el neokantismo, la fenomenología y la filosofía de los valores, el existencialismo y el historicismo... Aunque, no. Estos últimos ya no pude acogerlos como la verdad... Ya estaba escarmentado por la sucesión de las verdades anteriores... Pues ¿a qué puede mover semejante sucesión histórica 
-biográfica de verdades, semejante sucesión vivida, mucho más que la sucesión del pasado sabida por la Historia; a qué sino al escepticismo?" (OC XVII, p. 60).

27. Véase también, sobre todo esto, $O C$ VI, p. 52, y el importante prólogo a las Meditaciones cartesianas, ya citado, en OC VII, pp. 291 s. Por lo demás, se encuentran varias apreciaciones positivas de la fenomenología en las obras de Gaos; cito como ejemplo: "la que puede juzgarse ya definitivamente como la más importante de las filosofías contemporáneas, la fenomenología de Husserl" (OC VII, p. 48); o al final del mismo prólogo: "es lo más probable que el futuro ratifique el juicio que predice en Husserl el filósofo más importante en suma de la novisima y actuạl edad filosófica" (OC VI, p. 299), y luego: "No obstante las seductoras novedades posteriores a él, a Husserl habrá que volver, de él habrá que partir, durante bastante tiempo aún, hasta que haya advenido definitivamente el de tratarle como un gran clásico más. Porque esta necesidad de volver a él y partir de él anticipa desde ahora la clasicidad de su obra" (pp. 299 s.). Y ésta otra: "De Husserl estuve preso lo que ya puntualicé - por mor de la actualidad, no precisamente porque me gustara y atrajera de ninguna manera singular. $Y$ por mor de la historia volví a él en algunos de mis pasados cursos [...]. Pero cuando más recientemente tuve que volver a ciertas partes de las Investigaciones, para refrescar el recuerdo de ellas, ya muy marchito y macilento por obra de lustros de olvido - amigos míos, qué sorpresa, encontrarlo tan formidablemente analítico, abundante, riguroso, ejemplar de ciencia y conciencia filosófica: va a haber que volver a él, en cuanto se pueda - io es una erupción de ciencismo?" (OC XVII, p. 72).

28. Véase el importantísimo "Discurso de filosofía", escrito entre fines de 1953 y principios de 1954 y publicado en Discurso de filosofía y otros trabajos sobre la materia, Universidad Veracruzana, Xalapa, México, 1959 (Biblioteca de la Facultad de Filosofia y Letras), pp. 13-30. En él, Gaos distingue: "Hay en la filosofia dos partes: una parte que puede llamarse 'fenomenológica', por versar sobre los fenómenos inmanentes de este mundo, de esta vida; y una parte metafísica, la que se ha esforzado por saber, sobre todo cientificamente, del más allá, de la otra vida, del otro mundo" (p. 13), para luego esbozar su noción de la única filosofía "hacedera a estas alturas de la historia" con un "adiós a los sistemas metafísicos del universo en lo que tienen de seudocientífico-metafísicos, no en lo que contienen de fenomenología" (p. 30). Véase también una nota en que Gaos resume los puntos en que ese mismo "Discurso" precisa su posición "relativamente a la Filosofía", y en la cual afirma el valor "científico de las partes o disciplinas no metafísicas de la Filosofía y de las ciencias mismas" ("Selección de la aforística inédita", OC XVII, p. 255). Por lo demás, ya la mera distinción entre metafísica y ciencia, o, para el caso, entre metafísica y fenomenología, tiene en el pensamiento de Gaos una vasta serie de resonancias y vinculaciones que por desgracia no podemos registrar aquí. Véase por ejemplo, sobre la distinción equivalente entre Weltanschauung y filosofía cientifica, la nota 10 del texto "Notas sobre Husserl" (parte de un Homenaje a Edmund Husserl, realizado en 1959 en una sesión pública del Seminario de Filosofía Moderna de la Facultad de Filosofía y Letras de la UNAM, y publicado en el Anuario de Filosofia, 
año I, México, 1961, p. 149). Y esta precisión: "En la medida en que en la metafísica clásica entra la ontología y hasta la crítica, es la fenomenología metafísica. Lo único de la metafísica clásica que no entra en la fenomenología es la teología, porque Husserl se apresura a poner a Dios entre paréntesis y no llega a ocuparse otra vez de él. Su Weltanschauung es la de un indiferente en materia de religión típicamente moderno." ("Notas sobre Husserl", op. cit., p. 147, nota 7. En el mismo sentido, cfr. el capítulo 4 de En torno a la filosofía mexicana, nota 17, p. 133.) Sobre estos temas, véase el "Prólogo" de Fernando Salmerón a OC XIII, especialmente en p. 13.

29. "Notas sobre Husserl", op. cit., nota 4, p. 145.

30. Más adelante, precisa la cuestión así: "La posible imposibilidad de una ciencia, objetiva, intersubjetiva universal, es decir, por lo menos dentro de la vida de la Humanidad, de los fundamentos o principios de todo, y si se comprobase, su razón de ser" (ibid., p. 149). Pero ya aquí Gaos tiene su respuesta: "Es como si pensar 'principio de todo' y a la postre tener que pensar 'principios dentro de la vida individual' o 'subjetivos', fuese una misma cosa: como si fuese una misma cosa pensar totalidad y subjetividad o dentro de la vida individual" (pp. 148 s.).

31. La exposición de esa "razón" nos llevaría al núcleo mismo del "sistema" último de Gaos presentado en estas obras. Para los efectos de este artículo, basten las citas siguientes: "tal objeto [lo existente] es el más subjetivo de todos, el único absolutamente subjetivo, o en rigor, el único subjetivo, sin más [...]. Y tal es el objeto de - las filosofías, así, en plural, forzosamente, por lo mismo acabado de decir. Tal sería la explicación última de la pluralidad de filosofías cada una en conjunto subjetiva o personal" (De la filosofía, OC XII, p. 413). Y en el mismo sentido, Del hombre: "El filósofo no deja fuera de su concepción nada, nada ni siquiera de sí mismo, o menos que de nada de sí mismo. ¿Cuál es la consecuencia de esto [...]? Que el objeto de la filosofía, lo existente, nada abstracto, la concreción misma, no puede menos de ser absolutamente subjetivo: es el objeto subjetivo por excelencia. Y por eso tampoco pueden menos de ser subjetivas las filosofías como lo son de hecho, de hecho histórico. Lo anterior no es ninguna tesis en favor de la subjetividad de la Filosofía; es una teoria explicativa del hecho de que la historia de la Filosofia sea una historia de filosofías personales" (OC XIII, p. 564).

32. Hay más: esta filosofía de las esencias y de la conciencia pura es Weltanschauung "en la medida en que la Crítica de la razón pura sea Weltanschauung. Lo que quiere decir que en la misma medida en que Kant era filósofo, lo fue Husserl. Dicho sea en su demérito, con fidelidad a sus propias valoraciones predicativas" (p. 148). Además, "el soberbiamente anti-historicista e incientíficamente filósofo Husserl" "no quiso oír" "la lección de escarmiento" de "la historia de la filosofía" (p. 148). Y, dicho sea de paso, en una nota al pie: "La fenomenología es una generalización infundada de la filosofía de las matemáticas, injertada en la idea agustiniano-cartesiana de la refundamentación de la certeza ab initio; de una evidencia no objetiva, sino subjetiva" (p. 146, nota 6). 
33. Publicada en Symposium sobre la noción husserliana de la Lebenswelt, UNAM, Centro de Estudios Filosóficos, México, 1963, pp. 19-24.

34. Entre estas anotaciones, dos merecen una mención aparte: una en la línea 2 de la p. 83, que dice "ojo a la coma!", en un lugar en que la existencia de una coma es justamente decisiva para el sentido de la frase. La otra (que representa una excepción a lo que acabamos de decir en el texto), se encuentra en el segundo párrafo del § 105, p. 217, línea 2 desde abajo: Gaos anota "noemáticos?" donde la palabra alemana correspondiente es "noetischen", cuya traducción sería "noéticos". La traducción definitiva de Gaos en su versión castellana (véase cualquiera de las tres ediciones citadas en la nota 2, p. 253, línea 10 desde abajo) es "noemáticos", aunque no la aclara de ningún modo ni llama la atención del lector sobre su discrepancia respecto del texto original. Sin que esto signifique emitir un juicio sobre este punto, vale la pena hacer notar que tanto las tres ediciones alemanas hechas en vida de Husserl, como las dos publicadas dentro de Husserliana (la ya citada edición de Biemel de 1950 y la nueva edición de Karl Schuhmann de 1976), las cuales toman en cuenta incluso las anotaciones marginales hechas por Husserl en sus propios ejemplares, han mantenido la misma palabra: noetischen (véase la última de las citadas: Edmund Husserl, Ideen zu einer reinen Phänomenologie und phänomenologischen Philosophie, Erstes Buch: Allgemeine Einführung in die reine Phänomenologie, Neu herausgegeben von Karl Schuhmann, 1. Halbband, Text der 1.-3. Auflage (Hua III/1), Martinus Nijhoff, La Haya, 1976, p. 243, línea 2).

35. Véase su ficha completa al final de la nota 34. Por cierto, también en Hua III/1 (H) se da al margen la paginación de la edición original de la obra, que es idéntica a la de $\mathbf{E}$.

36. Ya también citada por nosotros en la nota 2 .

37. Uno de los poquísimos casos, no hay duda, en que a Gaos le llegó a "estorbar lo negro" en su vida.

38. Edmund Husserl, Ideen zu einer reinen Phänomenologie und phänomenologischen Philosophie, Erstes Buch: Allgemeine Einführung in die reine Phänomenologie, Neu herausgegeben von Karl Schuhmann, 2. Halbband, Ergänzende Texte (1912-1929) (Hua IIL/2), Martinus Nijhoff, La Haya, 1976.

39. Véase, por ejemplo, DI, pp. 74-75; OC VII, pp. 45, 63, 94, 105; OC XII, pp. 401403, 413-414; OC XIII, p. 437; OC XVII, pp. 119-120, 124, 137.

40. Lo afirma en OC XVII, pp. 119-120.

41. Sobre esta liga entre soberbia y principios, cfr. OC VI, pp. 62-63, 87, 94 y 105; OC XVII, pp. 117-120 y 124. 
42. Véanse las lecciones XVI ("Los conceptos individuales") y XVII ("La individualidad: inefabilidad y contingencia") de la primera (OC XII, pp. 124 y 133), y las lecciones XVI ("La función del pensamiento. La objetivación individual") y XVII ("La objetivación individual (conclusión)") de la segunda (OC XIII, pp. 221 y 235).

43. Del hombre, lección XI, OC XIII, p. 158.

44. La cuestión se plantea por vez primera en la lección XIV de la primera parte $(O C$ XII, p. 109), y atraviesa la obra hasta la lección VI de la segunda parte (p. 267). Su exposición final como antinomia se halla en la lección XVI de la segunda parte (p. 382).

45. Passim, pero véanse en particular las lecciones IX, XXII (titulada "La naturaleza del pensamiento") y, finalmente, su exposición como antinomia en la lección XXXVIII (OC XIII, p. 477 s.).

46. Véase la sección anterior ("Gaos sobre Husserl") de esta reseña.

47. Cfr. la lección VI de la segunda parte (OC XII, p. 263).

48. Véase principalmente De la filosofía, lección XVI de la segunda parte (OC XII, pp. 379-381). Del hombre (OC XIII, p. 566).

49. Véanse la lección XXII de la primera parte y, de nuevo, la lección VI de la segunda parte (OC, p. 268) y la XIX de esta misma (p. 413), de De la filosofia. Y en Del hombre, véanse las lecciones XIVI y XIVII (y en particular, en la última, las pp. 565-566 de OC XIII).

50. En Del hombre, sobre este parágrafo Gaos dice: "Pero las autoridades dicen que la Física está en trance de renunciar a todo 'modelo', para quedarse en una pura formulación matemática de los fenómenos mismos, porque el comportamiento de éstos es de una complejidad 'inimaginable'. Hace ya más de medio siglo que Husserl dio a esta concepción puramente fenomenológico-matemática de la Física, la formulación insuperable que se lee en el $\S 52$ de las Ideas, al que remito a aquel de ustedes lo bastante curioso para irse a leerlo." (OC XIII, p. 153.)

51. Véase por ejemplo Confesiones profesionales, OC XVII, pp. 119-120: "Por esto es el esencial destino de la Filosofía el idealismo trascendental, la filosofía del sujeto intelectual autárquico y condición de posibilidad de todo lo demás, incluso de la $\mathrm{Di}$ vinidad, cuando a ésta no la identifica consigo mismo; en suma, la. .. la. .. soberbia -de un Hegel, de un Kant." Y De la filosofía, segunda parte, XVI, OC XII, p. 380: "Una consecuencia más del idealismo trascendental es que el sujeto trascendental no pueda menos de concebirse a sí mismo como único; lo que quiere decir que el mísero sujeto que es cada uno de nosotros mientras se concibe a sí mismo como parte de su objeto total, acaba concibiéndose a sí mismo en la máxima sublimación 
o con la máxima sublimidad literalmente 'concebible' y, forzosamente, dejando a sus congéneres seguir en su mísera condición de partes de su objeto total, o dejando él de ser congénere de ellos en una absoluta 'soledad' —que viene de 'solo'. Consecuencia final: concebirse a sí mismo como - Dios."

52. Véanse por ejemplo las citas que tomamos de su ponencia en el "Simposio sobre la noción husserliana de la Lebenswelt" al final de nuestra sección anterior, "Gaos sobre Husserl". 